http://dx.doi.org/10.18232/20073496.1230

Artículos

\title{
Comparación del índice de salarios reales de una familia minera de Real del Monte de los siglos XVIII y XIX
}

\section{Real wages index of a mining family in Real del Monte 18th and 19 th centuries}

Elías Gaona $1, *$ iD 0000-0003-2630-219X

${ }^{1}$ Universidad Autónoma del Estado de Hidalgo, Pachuca, México.

*Correspondencia: elias_gaona3473@ueh.edu.mx

Resumen. Real del Monte, durante los siglos XviII y xix, se caracterizó por ser una de las principales zonas productoras de plata de Nueva España. En la década de 1760, las minas dieron origen a uno de los hombres más ricos del virreinato, Pedro Romero de Terreros. Ya a comienzos del siglo XIX, la región minera se posicionó en cuarto lugar en la producción de plata de toda la zona virreinal. Debido a la importancia que alcanzó Real del Monte como zona minera durante los siglos XVIII y XIX, se analiza aquí la evolución histórica de los salarios reales de las familias de los mineros-barreteros entre 1768 y 1900 y se comparan con los de otras ciudades europeas y asiáticas durante el mismo periodo. La hipótesis es que los salarios reales de los mineros-barreteros de Real del Monte fueron disminuyendo a lo largo del tiempo hasta alcanzar niveles de subsistencia a finales del siglo xIX, mientras que los de las ciudades europeas y asiáticas iban en ascenso.

Palabras clave: Real del Monte; salarios reales; cesta de bienes; calorías mínimas; costo de subsistencia.

Abstract. Real del Monte, during the 18th and 19th centuries, was characterized as one of the main silver producing areas of New Spain. In the 1760s, the mines gave rise to one of the richest men of the viceroyalty, Pedro Romero de Terreros. At the beginning of the 19th century, the mining region ranked fourth in

CÓMO CITAR: Gaona, E. (2022). Comparación del índice de salarios reales de una familia minera de Real del Monte de los siglos XVIII y XIX. América Latina en la Historia Económica, 29(2), 1-32. DOI: 10.18232/10.18232/20073496.1230

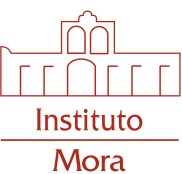


silver production in the whole viceroyalty. Due to the importance that Real del Monte reached as a mining area during the 18th and 19th centuries, the historical evolution of the real wages of the families of the miners-barreteros between 1768 and 1900 is analyzed and compared with that of other European and Asian cities during the same period. The hypothesis is that the real wages of Real del Monte's minersbarreteros decreased over time until they reached subsistence levels at the end of the 19th century, while those of European and Asian cities were on the rise.

Key words: Real del Monte; real wages; basket of goods; minimum calories; cost of subsistence.

JEL: N30; N33; N35; N36.

Recibido: 9 de julio de 2020.

Aceptado: 22 de junio de 2021.

Publicado: 14 de febrero de 2022.

\section{INTRODUCCIÓN}

Real del Monte fue una de las principales zonas productoras de plata de Nueva España. En 1774 ocupó el primer lugar como productor del metal argentífero, al representar $66 \%$ de la plata producida, seguido de Guanajuato con $24 \%$. Ambas regiones constituyeron $90 \%$ del total de la plata producida en la principal colonia de España. A comienzos del siglo xix se posicionó en el cuarto lugar, después de Guanajuato, Catorce (San Luis Potosí) y Zacatecas. ${ }^{1}$

El estudio de esta zona minera resulta de interés debido a que fue el lugar en donde se inició el primer movimiento huelguístico de importancia del que se tenga noticia en Nueva España. Esta revuelta de trabajo, acaecida en 1766, fue relevante por el número de mineros que laboraban en la zona, alrededor de 2 000. La causa de la asonada fue la intención del propietario de las minas, Pedro Romero de Terreros, conde de Regla, de suprimir el partido, que era una forma de remuneración que complementaba de forma importante el salario de los mineros, hasta el punto de suponer habitualmente una cantidad superior al salario.

El partido era la división del metal extraído de las minas entre los dueños de estas y los barreteros, una vez que estos hubieran cumplido con el tequio. El tequio era la cantidad de metal que debían extraer los barreteros de las minas tomando en cuenta la dureza o blandura de la veta durante su jornada laboral de doce horas. Si cumplían con el tequio antes de las doce horas, digamos, por ejemplo, en diez horas, entonces el partido era lo que obtenían los barreteros en las dos horas restantes.

Por otro lado, los barreteros laboraban con una barra de hierro en boca y punta, de poco menos del alto de un hombre, o con una cuña del mismo metal que clavaban con el golpe de un martillo (Cruz, 2016). Según Bernstein (1964), los barreteros eran la columna vertebral del sistema de trabajo minero en el porfiriato y los años veinte. ${ }^{2}$ Sin embargo, ya desde la época colonial era el oficio esencial en las minas. En ellas había alrededor de 30 oficios, siendo el de los barreteros el más numeroso. En 1768 eran 567 trabajadores con ese oficio, cifra que representaba $27.21 \%$ del número total de trabajadores, y en 1863 había 440 barreteros, es decir $34.32 \%$ del total (Gaona, 2019, p. 167).

\footnotetext{
${ }^{1}$ Véanse Carbajal (2002) y Humboldt (2011).

${ }^{2}$ Debido a la importancia de los barreteros en las minas mexicanas, el índice de los salarios reales calculados será el de estos trabajadores y el de sus familias.
} 
Algunos autores han identificado a los trabajadores mineros de México de los siglos XVIII y XIX como "aristocracia del trabajo" o "elite trabajadora", por los "altos salarios" que devengaban. Una manera de comprobar si eran trabajadores de elite es conocer y comparar sus salarios nominales con los de otros trabajadores, además de conocer sus salarios reales. Los salarios nominales de los mineros-barreteros, durante todo nuestro periodo de estudio, permanecieron constantes, no obstante, los salarios reales sufrieron modificaciones, siempre con una tendencia negativa, hasta alcanzar niveles de subsistencia a finales del siglo XIX.

En este trabajo se calcula y analiza el índice de salarios reales de las familias mineras de Real del Monte de 1768 a 1900 y se compara con otros índices de ciudades europeas y asiáticas para ver quién tenía mayores índices de bienestar. El artículo está estructurado, primero, con el análisis de los salarios nominales de los trabajadores de Real del Monte; segundo, con la revisión de la literatura en relación con los salarios reales (índices de bienestar); tercero, la presentación de la metodología para calcular los salarios reales; cuarto, el estudio de la cesta de bienes de precios de consumo, además de que se presentan y analizan los índices de salarios reales de una familia realmontense; sexto, se estudian los índices de bienestar de Real del Monte en relación con otras ciudades del mundo y, finalmente, se presentan las conclusiones.

\section{Salarios nominales de los trabajadores de Real del Monte}

En esta sección se analizan los salarios de los barreteros, junto con otras ocupaciones no mineras: peones de la construcción, oficiales albañiles, peones de hacienda y maestras cigarreras; estas últimas eran la que ganaban más, recibían ocho reales (equivalentes a 100 centavos al día o un peso) (véase gráfica 1). Sólo contamos con datos de dos años, 1798 y $1808 .^{3}$ No obstante, es lo que podrían haber ganado antes de 1798 y después de 1808, debido a que los salarios de los y las trabajadoras mexicanas se conservaron inmutables por décadas. ${ }^{4} \mathrm{El}$ año de 1798 hace mención a una fábrica de cigarros de Puebla y el de 1808 remite a una en Querétaro.

En relación con el mayor salario de las cigarreras podemos señalar que esto se debía a las siguientes características que manifiesta Saloma (2000, p. 31): a) tenían experiencia en el oficio; $b$ ) eran catalogadas como cuidadosas; $c$ ) diestras; $d$ ) comprometidas, y $e$ ) menos problemáticas que los trabajadores varones.

Por otro lado, los albañiles oficiales ocuparon el segundo lugar por sus salarios entre $1793 \mathrm{y}$ 1887, es decir, 62, 68, 75 y 81 centavos diarios. Nunca superaron el peso diario de las maestras de mesa de las fábricas de cigarros. Ambos salarios se obtenían en la ciudad de México.

Los barreteros mineros de Real del Monte se localizaban en tercer lugar dentro de los oficios que analizamos, con un salario diario de 50 centavos por día. Al comparar los salarios de los barreteros con los de las trabajadoras de las fábricas de cigarros, el de estas últimas era muy superior al de los barreteros mineros, quienes ganaban $50 \%$ menos que los trabajadores y trabajadoras de las fábricas de cigarros. En penúltimo lugar estaban los peones de la construcción, con salarios diarios de 37 y 43 centavos en la ciudad de México y Guadalajara. En último lugar se encontraban los peones de hacienda con un salario mínimo de 25 centavos.

${ }^{3}$ 1798. Instituciones coloniales, Indiferente virreinal, caja 6222, exp. 001 (Renta del tabaco, caja 6222). Archivo General de la Nación (en adelante AGN); 1808. Instituciones coloniales, Real Hacienda, (008), vol. 1015, exp. 8. Archivo Histórico de Hacienda (en adelante Анн).

${ }^{4}$ Los salarios de los mineros permanecieron constantes por décadas a pesar de que hay indicios de que la productividad de los mineros incrementó debido a los avances tecnológicos de la época (Gaona, 2019, p. 234). 


\section{GRÁFICA 1. SALARIO DIARIO DE DIFERENTES TIPOS DE TRABAJADORES, 1719-1891 (PESOS Y CENTAVOS)}

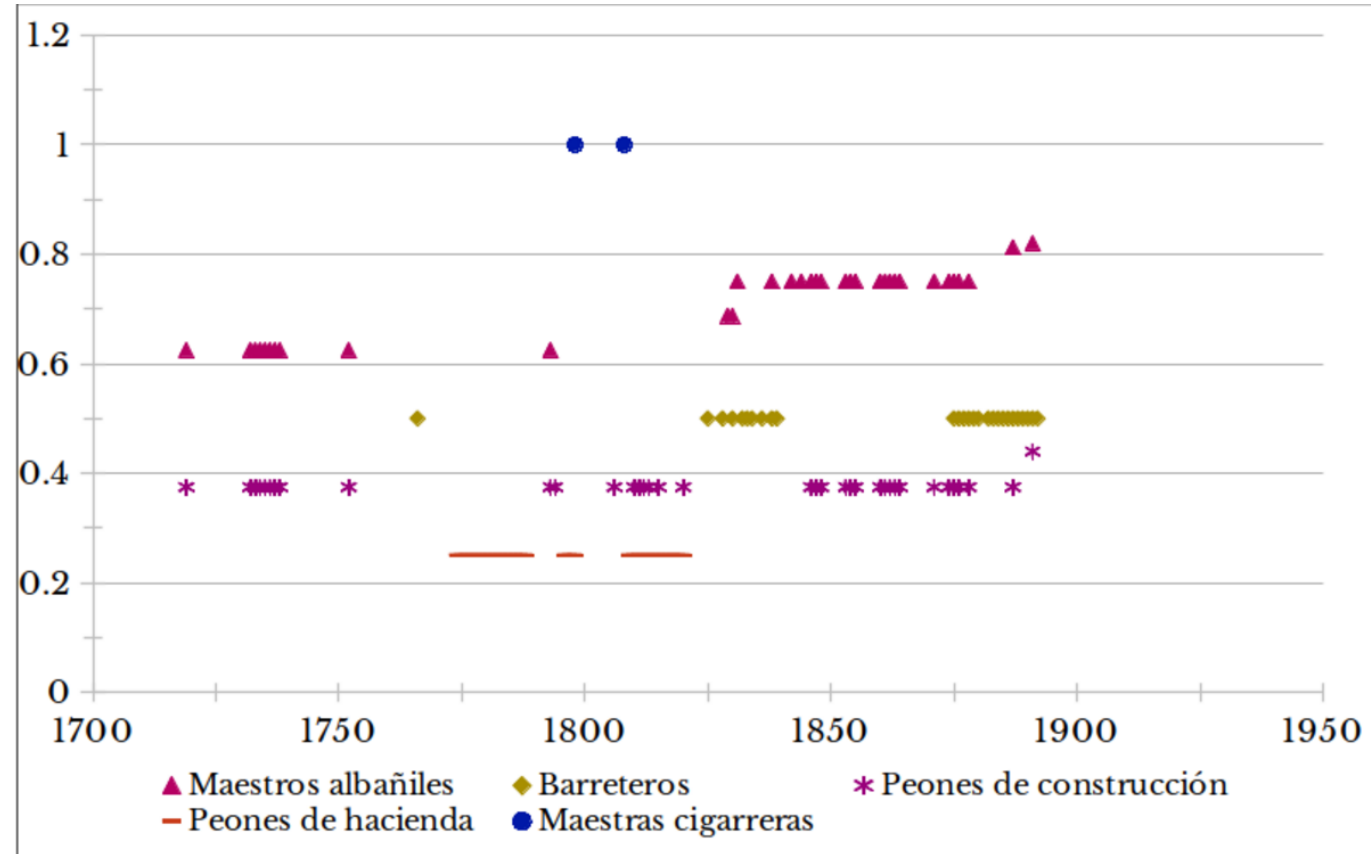

Fuentes: Maestros albañiles en Estante 3, tabla Iv, vols. 1-2, Estante 17, tabla v, vols. 1-2, Estante 18, tabla II, vols. 1-10, Estante 24, tabla II, vols. 1-11. Archivo Histórico del Colegio de San Ignacio de Loyola (en adelante AHCSIL). Barreteros, 1766 (Chávez, 1987). Archivo Histórico y Museo de Minería (en adelante AHMM-AC), 1825-1850. Sección: vII. Negociaciones, Minas, Minas de Regla, vols. 1-56, 1874-1892. Contaduría General, Memorias, Memorias Semanarias, vols. 40-111. Peones de Hacienda (Gibson, 2003). Peones de construcción (Quiroz, 2005). Bernstein (1964, p. 86) afirma que los salarios en la minería mexicana durante el siglo xix eran de 50 centavos al día, por esta razón se asume que el salario de los barreteros se mantuvo en esa cantidad de $1892 \mathrm{y}$ hasta 1900. Maestras cigarreras en Indiferente Virreinal, Tabaco, exp. 1, caja 6222, 1801, 1822. AGN.

Observamos estabilidad en los salarios que percibían los trabajadores de México. En relación con esta inmovilidad, Gibson (2003, p. 257) señalaba que "[desde] 1630 hasta fines del periodo colonial [...] los salarios fueron mucho más estables. En algunos casos, las tasas de fines del siglo XviII fueron idénticas a las de 150 años antes."

Respecto a este mismo tema, Quiroz (2005) manifestó que:

El estado actual de los conocimientos sobre el comportamiento de los salarios de los jornaleros hacia fines del siglo XVIII, indicaría que estos permanecieron invariables [...]. Situación que puede ser ratificada con nuestras fuentes de jornales urbanos que demostrarían que los salarios pagados en obras de construcción dentro de la ciudad, se mantuvieron desde comienzos del siglo hasta por lo menos los años sesenta totalmente invariables (p. 238).

¿A qué se debió que los salarios de los novohispanos y de los mexicanos después permanecieran sin cambios? Existen indicios de que, en el caso de los mineros de Real del Monte, se debió a cuestiones políticas de las empresas. De esta forma, tenemos que cuando los ingleses quisieron 
reactivar las minas de Real del Monte, después de que México obtuvo su independencia, comenzaron a contratar trabajadores, en 1823, con un salario de cuatro reales, equivalentes a 50 centavos, misma cantidad que pagaba el conde de Regla en 1766, es decir, 57 años antes. El declive de la producción de plata en esa zona ocasionó que, en 1871, la compañía, propiedad de mexicanos desde 1849, decidiera abolir los destajos y notificar a los barreteros que su salario pasaba a ser de un peso al día. ${ }^{5}$ Los barreteros, al conocer la noticia, se inconformaron, pues sabían que el cambio en la forma de pago significaba una rebaja en sus ingresos, y demandaron que se continuara con los destajos.

Un mes después, el 29 de julio de 1872, la dirección se retractó de la proposición de pagar un peso por día. La junta directiva manifestó al director que nada adelantarían con ofrecer mayores sueldos si la compañía no podía satisfacerlos, por lo que el salario de 50 centavos se mantuvo vigente. ${ }^{6}$ Ante tales hechos, podemos afirmar que la fijación de los salarios es siempre el resultado de un proceso político.

Por otro lado, es una opinión muy extendida en la literatura académica que los mineros eran trabajadores muy bien pagados. Comparten esta opinión contemporáneos como Humboldt (2011), y autores como Brading (2015), Langue (1991) y Von Mentz (2001). A los mineros del siglo xviII Langue los calificaba como aristocracia del trabajo, mientras que Von Mentz considera trabajadores de elite a los mineros del siglo xIx. Según Humboldt (2011, p. 370), los mineros novohispanos eran los mejor pagados entre todos los mineros, al percibir un salario de entre 70 y 95 centavos diarios, mientras que Langue (1991) ubica como aristocracia del trabajo a quienes obtenían 87.5 centavos, como es el caso de un dinamitero. Por su lado, Von Mentz (2001) ubica como elite trabajadora a los que cobraban por su trabajo salarios mayores a los tres o cuatro pesos, como los maquinistas, mecánicos, motoristas y electricistas. Según estos criterios, los barreteros que ganaban 50 centavos diarios no entraban en la categoría de aristocracia ni de elite.

Además de los salarios de los barreteros, estos obtenían ingresos adicionales a través del partido. ${ }^{7}$ Determinar los ingresos extraordinarios que se obtenían por este concepto es complejo, debido a que no hay registros sistemáticos, pero sabemos que un barretero, además de los cuatro reales de salario (50 centavos), podía obtener tres o cuatro pesos por su venta (300-400 centavos o 24-32 reales). El 28 de julio de 1766 los barreteros de Real del Monte señalaban que: "apenas puede el barretero granjear cuatro o seis reales [50-75 centavos], cuando pudiera con buen metal, como el que saca a partir, granjear tres o cuatro pesos" (300-400 centavos o 24-32 reales) (Arellano, 1976). Es decir, los barreteros podrían obtener por la venta del partido unos 3.5 pesos diarios. Con estos ingresos, entonces sí podrían denominarse trabajadores de elite o aristocracia del trabajo.

Algunos niños trabajaban en las minas, pero sobre su salario disponemos de muy pocos datos. Entre 1881 y 1890, en las haciendas de beneficio de Guadalupe y Bartolomé de Medina, en Pachuca, los muchachos recibían por su salario 18 y 35 centavos, respectivamente (Canudas, 2005).

${ }^{5}$ El trabajo a destajo es aquel en el que la remuneración se pacta con base en la cantidad de unidades producidas, obras o labores que el trabajador realiza en una jornada determinada. Se conoce también como trabajo de obra o por labor. Fue con esta forma de pago con la que la empresa minera de Real del Monte intentó sustituir el ancestral sistema de partido. Recuperado de https://www.gerencie.com/contrato-de-trabajo-por-destajo.html

${ }^{6}$ Junta Directiva, Dirección a Junta Directiva, 1872, foja 352. Archivo Histórico de Mineral del Monte, Hidalgo, México (en adelante Анмм.)

${ }^{7}$ El partido consistía en conceder a los barreteros y a otros operarios una participación del mineral extraído (Moreno, 1976, p. 466). 
Es decir, 37.5 y $70 \%$ de los salarios de los barreteros de Real del Monte (50 centavos al día). En el caso de los niños que laboraban en esta última región, en las haciendas de Regla sus salarios, en 1900, eran de 18.75 y 25 centavos diarios, es decir, 37.5 y 50 \% más de lo que ganaban los barreteros. Con estos datos se puede suponer que, en promedio, ganaban alrededor de 25 centavos diarios.

Si sumamos el partido, el salario del padre y el del hijo, tendríamos un ingreso familiar diario de cuatro pesos con 25 centavos. Es decir, 3.5 pesos de partido, 0.5 de salario del padre y 0.25 del salario del hijo. El salario del padre junto con el de su hijo constituía $17.64 \%$ de sus ingresos totales, mientras que el partido representaba $82.35 \%$. Estos ingresos pudieron estar vigentes entre 1766 y 1839, tiempo en el cual se mantuvo el pago por salario y el partido, pero a partir de 1840 y hasta 1874 la forma cambió a destajo. Los ingresos que los trabajadores obtuvieron bajo esta forma de pago eran de 1.20, 1.30, 1.50 o 3.80 pesos al día. Si promediamos estos cuatro valores tenemos la cantidad de 1.95 pesos. Si a esta cantidad le sumamos el salario del hijo (25 centavos), tenemos un ingreso familiar de 2.20 pesos al día. A partir de 1875 se va a retomar el pago por salario (50 centavos al día) y el partido. De acuerdo con información de los propios barreteros, con el partido ahora sólo obtenían entre tres y 3.5 pesos quincenalmente, es decir, en promedio 1.75 pesos semanales. De los 50 centavos que ganaban, tenían que pagar $25 \%$ por los insumos que percibían, quedándoles un salario bruto de 37.5 centavos. Si dividimos el partido semanal (1.75) entre seis días trabajados, tenemos un ingreso extraordinario de 29 centavos. Por lo que el salario familiar en este último periodo (1875-1900) fue de 91.5 centavos en promedio: 37.5 del salario del padre, más 29 centavos por partido y 25 centavos del salario del niño.

\section{REVISIÓN DE LA LITERATURA}

Robert Allen (2001) confeccionó una canasta de consumo de los albañiles ingleses en la fase de la revolución industrial que contenía alimentos, ropa, lumbre, calefacción y costo de la vivienda. La canasta abarcaba una familia de cuatro integrantes. El resultado, situándolo en relación con el salario nominal de los trabajadores, dio paso a un coeficiente nombrado índice de bienestar.

El enfoque calcula los salarios reales como tasas de subsistencia, definidas como el número de canastas de consumo que los hogares podrían comprar con los ingresos anuales de un trabajador. Un valor de más de uno indica la posibilidad de adquirir más artículos a los estrictamente necesarios para subsistir o bien comprar artículos suntuarios. Proporciones de menos de uno sugieren que las familias enfrentaron graves dificultades económicas.

Por otro lado, Calderón et al. (2017) piensan que la técnica de Allen no es apropiada para medir con exactitud el bienestar de las familias, debido a que no incluye el trabajo de mujeres y de niños como parte de los ingresos familiares, dada la enorme evidencia sobre su contribución al presupuesto de la mayoría de las familias europeas urbanas. ${ }^{8}$ En otro orden de ideas, Humphries (2013) considera que Allen minimiza las necesidades calóricas de niños y mujeres, y no coincide con la conversión de niños y mujeres a equivalentes masculinos adultos. Allen estimó en 1936 el mínimo de calorías para subsistir de un adulto de México, el Potosí y Bogotá, aunque Santilli (2020) considera que estas eran reducidas porque se creía que en la realidad el consumo debía ser mayor.

\footnotetext{
${ }^{8}$ En sus conclusiones señalan que para conocer la evolución de los niveles de vida o bienestar sería preciso estimar los ingresos familiares.
} 
A pesar de las críticas, el método de Allen se popularizó y fue empleado por él y por sus seguidores alrededor del mundo como un procedimiento útil para comparar momentos y espacios muy diversos, es decir, esta técnica ha sido utilizada en varios casos históricos que han superado el marco de Gran Bretaña, incorporando varias ciudades europeas, India, China, Estados Unidos y América Latina (Allen et al., 2011; Allen, Murphy y Schneider, 2012; Arroyo, Davies y Van Zanden, 2012; Arroyo, 2013; Challú y Gómez-Galvarriato, 2012; Panza y Williamson, 2017; Santilli, 2020).

En relación con Iberoamérica se han realizado trabajos sobre Argentina, Bolivia, Colombia, Chile, España, México, Perú y Venezuela; enseguida los repasaremos. Llorca-Jaña y NavarreteMontalvo (2015) calcularon los salarios reales de los trabajadores de la construcción en Santiago de Chile entre 1788 y 1808 . Utilizaron el método de Allen (2001) para calcular los salarios reales, en términos de índices de bienestar. Sus principales conclusiones fueron: $a$ ) los salarios reales de los trabajadores no cualificados se mantuvieron por encima de los niveles de subsistencia durante todo el periodo de estudio, dada la escasez de mano de obra en Santiago durante este periodo, $b$ ) una proporción significativa de trabajadores cualificados de la construcción ganó entre dos y tres veces más que los trabajadores no cualificados. ${ }^{9}$

Arroyo (2013) calculó los salarios reales de trabajadores no cualificados (sirvientes, porteros y peones) de Caracas, concluyendo que, aunque tras la independencia los estándares de vida eran extremadamente bajos, hacia 1870-1880 se observó un aumento sustancial del bienestar, interrumpido a fines de siglo por el incremento de los precios. La autora concluye que, si bien hubo mejora durante el siglo xix, los niveles de vida fueron menores a los de otras economías en vías de desarrollo.

Arroyo, Davies y Van Zanden (2012) presentan una serie de largo plazo (1530-1820) de salarios reales en América Latina, en específico, Argentina, Bolivia, Colombia, Chile, México y Perú. Los autores concluyeron que en América Latina había escasez de mano de obra, lo que trajo como consecuencia salarios muy por arriba del nivel de subsistencia en Argentina, Bolivia y México, comparables a los del noroeste de Europa. En México los salarios reales de los trabajadores de la construcción estuvieron muy por encima del nivel de subsistencia hasta el siglo xviII.

Según Allen et al. (2011), a fines del siglo XviII, en las zonas rurales de México, los salarios aumentaron cerca de 1.75 sobre el nivel de subsistencia, mientras que en las metrópolis ganaban alrededor de tres veces el nivel de subsistencia.

Dobado y García (2010) calcularon el salario real de los mineros en Nueva España en 1803, deflactando el salario nominal a partir de los precios del trigo, centeno, maíz, arroz y carne. La opción de calcular el poder adquisitivo de los salarios nominales para un solo año, aunque no del todo satisfactoria, la justificaron por la carencia de canastas de consumo en el periodo novohispano. Sus resultados fueron: $a$ ) los salarios en granos de los mineros cualificados de Nueva España eran más bajos que los de los trabajadores cualificados de Estados Unidos, pero mayores que los de Almadén, Amberes, Estrasburgo, Gdansk, Leipzig, Madrid, Milán, Nápoles, Palencia y Viena. Es decir, los salarios mineros en la economía tardocolonial eran elevados en perspectiva internacional; b) los salarios en términos de un bien superior (la carne) eran superiores, es decir, el acceso a la proteína animal era mucho más fácil para los mineros de Nueva España. La mayor capacidad de compra, en términos de carne, se debió a los precios relativamente bajos de esta.

${ }^{9}$ Por niveles de subsistencia vamos a entender las calorías mínimas que necesita una persona para sobrevivir. Más adelante nos ocuparemos de ellas. 
Para Calderón et al. (2017) la metodología desarrollada por Allen (2001) para calcular la relación de bienestar o el índice de salario real ha permitido una interesante comparación de los niveles de vida de los trabajadores en ciudades de diferentes continentes entre finales de la edad media y el siglo xIx. No obstante, tal y como lo señalamos arriba, consideran que su metodología no es adecuada para medir con precisión la forma de vida de las familias de los asalariados urbanos, por lo cual es importante desarrollar otra metodología que permita una mejor evaluación de los ingresos, modelos de consumo y gastos de las familias trabajadoras urbanas. Creen que es importante la inclusión del trabajo de niños y mujeres como parte de los ingresos familiares, dada la considerable evidencia sobre su contribución no menor al presupuesto de la mayoría de las familias europeas urbanas en el periodo preindustrial, es decir, la familia sería "la verdadera unidad de trabajo". El periodo que estudian es 1680-1800 para Madrid y 1759-1791 para la ciudad de México, pero únicamente muestran la tendencia de los salarios reales de Madrid. En 1600, en esta ciudad los salarios reales de los maestros albañiles eran insuficientes para obtener lo mínimo para sobrevivir, no obstante, la tendencia fue al alza, de tal forma que en 1800 con sus salarios podían adquirir dos canastas mínimas, es decir, dos veces las cantidades mínimas que una persona necesita para sobrevivir.

Con la metodología de Allen, Challú y Gómez-Galvarriato (2012) calcularon un índice de salarios reales de los albañiles de la ciudad de México. El periodo estudiado abarcó de 1730 a 1930. Concluyeron que los salarios reales eran altos en perspectiva internacional a mediados del siglo XVIII, sólo moderadamente por debajo de las ciudades del noroeste de Europa. Alcanzaron su punto más bajo al final del periodo colonial y durante la etapa de la independencia. Durante la era colonial tardía del reformismo borbónico y la expansión minera (1780-1800) hubo una disminución significativa de los niveles de vida, causada en parte por la alta extracción de recursos por la corona para combatir guerras contra sus rivales europeos. Los salarios reales se redujeron en 1780-1800 y cayeron aún más en 1801-1821. Entre 1825 y 1850 se recuperaron, pero experimentaron un colapso a mediados de siglo con los conflictos civiles. Cuando se logró la paz a finales de la década de 1860, los salarios reales se recuperaron, con una nueva caída dramática durante la revolución mexicana. ${ }^{10}$

En Santilli (2020), varios investigadores analizaron el nivel de vida a través de índices de bienestar de varios trabajadores de diversas regiones de Argentina: Buenos Aires, Jujuy, Mendoza, Santa Fe y Tucumán. El periodo que estudiaron fueron los siglos XVIII y XIx. Los índices de bienestar obtenidos mostraron valores positivos, con variaciones según la época y la región, pero en general superaron el nivel mínimo de subsistencia en forma creciente a medida que se avanzó en el tiempo, 1700-1900.

En las páginas siguientes se analizará en qué medida, durante los siglos XVIII y XIx, los trabajadores mineros novohispanos de Real del Monte tuvieron salarios reales por encima de los niveles de subsistencia. Para ello se elaborará un índice de salarios reales de una familia minera-barretera, realmontense, compuesta de cuatro integrantes: padre, madre y dos hijos. Seguiremos el método que Allen (2001) utilizó para calcular los salarios reales, con la diferencia de que calcularemos el ingreso familiar y no de una sola persona, tal y como lo manifestaron Calderón et al. (2017). De igual forma, mientras que en la técnica de Allen un elemento esencial son las calorías mínimas necesarias que requiere una familia para sobrevivir y los alimentos que las aportan, nuestras calo-

${ }^{10}$ Estos autores no mencionan el trabajo de mujeres y niños, ni sus aportaciones al ingreso familiar. 
rías y los alimentos que las proporcionan difieren de las que Allen estimó para algunos países de América Latina, México incluido. Son también diferentes a las que Challú y Gómez-Galvarriato (2015) calcularon.

\section{MÉTodo PaRa CaLcular los SALARIOS REALES (ÍNDICES DE BIENESTAR)}

En nuestro caso, para calcular la tasa de subsistencia o relación de bienestar, en lugar de tomar en cuenta el salario un solo trabajador, tomaremos el salario de dos personas: $a$ ) el del jefe de familia, es decir el papá y $b$ ) el de un hijo. No incluimos el salario de las mujeres porque, a pesar de que existen evidencias de que laboraban en la superficie de las minas, carecemos de datos sobre sus salarios, además de que alguien debía estar a cargo del hogar y de la crianza de los niños, debido a que así se acostumbraba (y continúa la costumbre). En cuanto a la inclusión de un hijo en el padrón de Real del Monte de 1768, 12.8 \% de los trabajadores eran hijos que trabajaban en las minas como: operarios, peones, faeneros, etcétera (Gaona, 2019, p. 280).

Se calcularon los ingresos anuales de una familia, padre e hijo. Y se procedió multiplicando el salario diario por cada trabajador y por el número de días trabajados en un año. Al salario monetario de los mineros-barreteros le agregaremos el partido, que era un ingreso adicional que podían obtener. Los días anuales de trabajo dependían del número de fiestas religiosas (Allen et al., 2012). Se puede agregar que también dependían de la demanda de trabajo por parte de los empresarios mineros, aunque esta es difícil de medir. Allen estimó el número anual de días trabajados entre 250 y 275. Challú y Gómez-Galvarriato (2015) toman 250 días. Mientras que para Santiago de Chile, Llorca-Jaña y Navarrete-Montalvo (2015) consideran 280 días.

De los 365 días, 52 eran domingos; de los 313 días restantes deduce 25 por fiestas religiosas y nueve por mal tiempo, quedando 280 días (Llorca-Jaña y Navarrete-Montalvo, 2015). Para Venezuela, Arroyo (2013) no dice nada al respecto. En este trabajo se tomarán también los 250 días propuestos por Allen.

Después, se calculó el coste de las necesidades mínimas de consumo de una familia. Allen (2001) supone que esta estaba compuesta por dos adultos y dos niños. En Real del Monte y de acuerdo con el censo de 1768, en promedio los hogares tenían dos hijos (Gaona, 2019, p. 281), lo que coincide con la hipótesis de Allen (2001), para quien una canasta familiar equivalía a la de tres hombres adultos. Si el consumo de calorías de una mujer es de aproximadamente cuatro quintas partes de las de un hombre, y los niños reciben incluso menos, el consumo de calorías recomendada de un hombre, una mujer y dos niños es aproximadamente igual a la de tres hombres (Allen et al., 2012, p. 875). Tal y como lo señalamos arriba, de acuerdo con Humphries (2013, p. 695), Allen subestimaba las necesidades calóricas de mujeres y niños, y no estaba de acuerdo con la conversión de mujeres y niños a equivalentes masculinos adultos. Allen estimó en 1936 el mínimo de calorías para subsistir de un adulto de México, el Potosí y Bogotá, por lo que el número total de calorías que requería una familia para subsistir era de 5808.

\section{Cesta de Bienes E ÍNDice de PRecios de CONSUMo}

$\mathrm{Al}$ realizar los cálculos de las calorías que requería una familia para subsistir de acuerdo con su edad y el esfuerzo físico que realizaba por la labor que desempeñaba, tenemos que nuestra familia modelo consumía en total 10628 , es decir 2657 calorías en promedio por cada integrante de la 


\section{GUADRO 1. GESTA DE CONSUMO POR PERSONA}

\begin{tabular}{lccc}
\hline Alimentos & $\begin{array}{c}\text { Gramos por } \\
\text { persona al día }\end{array}$ & $\begin{array}{c}\text { Cantidades por persona } \\
\text { al año }(\text { en } \mathrm{kg})\end{array}$ & $\begin{array}{c}\text { Calorías } \\
\text { por día }\end{array}$ \\
\hline Maíz & 450 & 164.25 & 981 \\
Frijoles & 100 & 36.50 & 151 \\
Carne & 200 & 73 & 580 \\
Manteca & 10 & 3.65 & 90.20 \\
Pan & 65 & 23.72 & 219.05 \\
Azúcar & 23 & 8.39 & 90.62 \\
Sal & 0.5 & 0.18 & 0 \\
Café & 13 & 4.74 & 10.66 \\
Total & - & - & 2122
\end{tabular}

Necesidades no alimentarias

\begin{tabular}{llll} 
Jabón & - & 2.60 & - \\
Algodón, lino & - & $5^{\mathrm{a}}$ & - \\
Velas y lámpara de aceite & - & 3.40 & - \\
Combustible & - & $4.20^{\mathrm{b}}$ & - \\
\hline
\end{tabular}

${ }^{\mathrm{a}}$ Metros, ${ }^{\mathrm{b}}$ millones de unidades térmicas británicas (BTU por sus siglas en inglés).

Fuente: elaboración propia con base en Allen (2001).

familia. ${ }^{11}$ Sin embargo, si tomamos esta última cantidad, al transformar las calorías a kilos de bienes que componen nuestra canasta, estos se elevan mucho, y en algunos casos resultan cantidades no creíbles. Por tanto, se optó por reducir las calorías, suponiendo que todos los integrantes de la familia realizaban actividades físicas ligeras. De esta forma, nuestras calorías se reducen de 10628 a 8 488. Si dividimos esta última cantidad entre los cuatro integrantes, tenemos que, en promedio, cada uno consumía 2122 calorías (véase cuadro 1), cantidad similar a la que proponen Calderón et al. (2017) para su cesta de subsistencia (2 118). ${ }^{12}$ De esta forma, nuestra cesta también será de subsistencia, en el sentido de que cubre las calorías gastadas por los miembros de la familia. Por ende, el mínimo de calorías requeridas por la familia será de 8488 , y no las 5808 que propone Allen et al. (2012).

Los salarios deberán ser comparados con un índice de precios al consumidor de una canasta básica, por lo que se construyó una, la cual está integrada de once bienes (véase cuadro 1). Todos los productos están convertidos a kilos, menos el carbón, que está en millones de unidades térmicas británicas, y el algodón y el lino, convertidos a metros.

${ }^{11}$ Para calcular el número de calorías se utilizaron las fórmulas propuestas por la Organización de las Naciones Unidas para la Alimentación. Véase Carbajal (2013, p. 5).

${ }^{12} \mathrm{Si}$ tomamos el peso promedio actual de la población mexicana (74.8 $\mathrm{kg}$ para hombres y $68.7 \mathrm{~kg}$ para mujeres) (Cherem, 2012), se tiene que las calorías necesarias que necesita una familia por el desgaste físico que sufren sus integrantes al realizar las diferentes actividades es de 10628.1 calorías, no obstante, y para no sobreestimar las calorías requeridas debido a que la estatura y el peso eran menores en el siglo XIx, suponemos que todos los integrantes realizaban actividades ligeras. Esta suposición permite reducir el número de calorías a 8487.8 . 
Utilizamos los precios anuales que encontramos en el Archivo General de la Nación (AGN), el Archivo Histórico de la Ciudad de México (ahcmx), el Archivo Histórico de la Secretaría de Salud (AHSs), el Archivo Histórico del Colegio de San Ignacio de Loyola (AHCSIL), el Archivo General del Estado de Hidalgo (АGEH), el Acervo Histórico y Palacio de Minería (AHPM) y datos encontrados en fuentes secundarias. El origen de los informes es variado: hospitales, hospicios y otras instituciones públicas. En caso de lagunas de información hemos completado las series utilizando la técnica de la interpolación, calculando precios promedios anuales.

Es importante señalar que, debido a la carencia de datos de precios de Real del Monte, se utilizaron los precios de los bienes de la ciudad de México, debido a la relativa "cercanía" entre ambas regiones, $107 \mathrm{~km}$. No obstante la crítica que se le puede hacer al trabajo por este hecho, consideramos que los cálculos realizados podrían ser una buena aproximación a los verdaderamente existentes en la región minera. Se realizó un modelo econométrico en donde se relacionan ambos índices. ${ }^{13}$ De acuerdo con ese modelo se dedujo que, en promedio, el costo estimado de los productos de Real del Monte entre 1766 y 1900 fue 20.7 \% superior al de la ciudad de México.

El índice de precios utilizado es el de Laspeyres, que mide el cambio en los precios que ocurriría en un periodo dado si se hubieran comprado los mismos artículos y en las mismas cantidades en un punto de referencia o periodo base. Una ventaja importante de este método es que siempre pueden hacerse comparaciones de precios, no sólo para cada periodo con el periodo base, sino también entre un periodo y otro. Su desventaja principal es que no tiene en cuenta los cambios producidos en los patrones de consumo en el periodo seleccionado (Levin y Rubín, 2004).

\section{Índice de salarios Reales de una familia de mineros de Real del Monte}

Si la relación entre los ingresos nominales: salarios y partido de una familia (padre e hijo) y el costo de una cesta familiar, la cual incluye alimentos, productos no alimenticios, ropa y renta, es igual a uno (1), entonces significa que un minero-barretero y su hijo ganaban los ingresos necesarios para mantener a una familia en el nivel de subsistencia, con las 2122 calorías señaladas arriba, las cantidades de ropa, combustible, velas y jabón que designan Challú y Gómez-Galvarriato (2015) para su cesta de pobreza. ${ }^{14}$

Relaciones de subsistencia de más de uno indican la posibilidad de adquirir más artículos (véase cuadro 1) o bien comprar artículos de lujo. Proporciones de menos de uno sugieren que las familias enfrentaron graves dificultades económicas. Para el caso específico que se está analizando, el índice de subsistencia en 1766, considerando el partido, fue casi 18 veces superior a lo estrictamente necesario para subsistir (véase gráfica 2). A partir de ese año caerá con altibajos. Entre 1766 y 1820 el punto más bajo se alcanzó en 1820 y fue de 2.2. Consumada la lucha de la independencia, México comienza la recuperación del salario real de los mineros realmonteses y de sus familias hasta alcanzar la cifra de 3.59 en 1846. A partir de este año, el índice de subsistencia va a descender de nuevo, probablemente por los conflictos armados que atravesó el país: $a$ ) la intervención estadunidense de 1846-1848 y la firma del Tratado de Guadalupe-Hidalgo, por el cual México

${ }^{13}$ Véase Anexo 1 al final de este trabajo, en donde se presenta el modelo.

${ }^{14}$ Las cantidades de ropa, combustible, velas y jabón que para Challú y Gómez-Galvarriato son de pobreza, para este trabajo serán de subsistencia debido a que las calorías elegidas (2 122) son de subsistencia, y que, por cierto, son mayores a las propuestas por los autores señalados como de pobreza, es decir, 1941 calorías de subsistencia. Si las calorías de subsistencia que proponemos son mayores, las cantidades no alimentarias también deben serlo. 


\section{GRÁFICA 2. ÍNDICE DE SUBSISTENCIA CON PARTIDO DE UNA FAMILIA REALMONTENSE, 1766-1896}

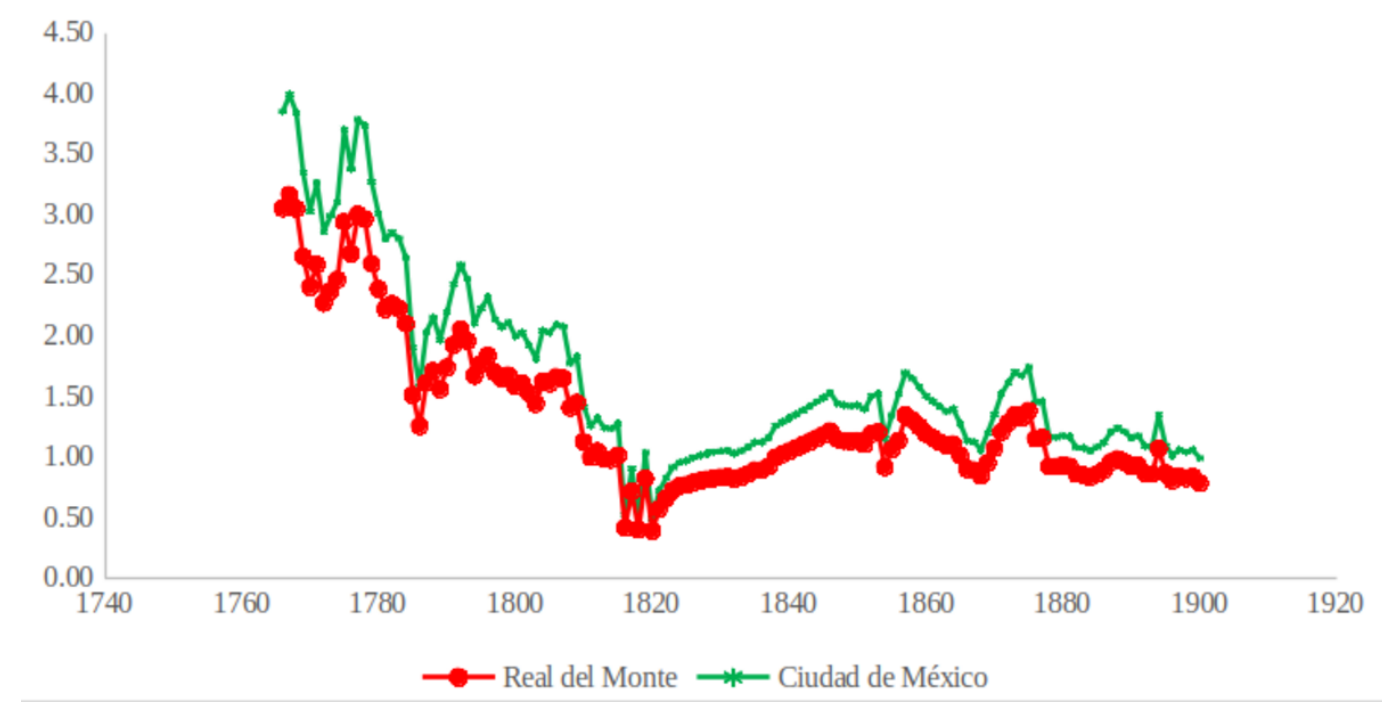

Fuente: elaboración propia con base en salarios de gráfica 1, véanse fuentes en anexo 2.

perdió más de la mitad de su territorio y $b$ ) la guerra entre liberales y conservadores, en el marco del segundo imperio mexicano, en 1865 y 1866. Entre 1878 y 1900 el índice de subsistencia fue de 1.3 .

El índice de salarios reales de los barreteros de Real del Monte junto con su familia cayó drásticamente de 1766 hasta 1900, al pasar de 17.5 a 1.15, aunque nunca alcanzó niveles de subsistencia. Esta caída se debió a que los salarios permanecieron inalterables durante más de 130 años; a que el partido desapareció por un tiempo (1840-1874) y luego disminuyó considerablemente, $\mathrm{y}$ a que los precios se incrementaron de manera considerable.

Si tomamos en cuenta los salarios de los barreteros sin partido, entonces tenemos que, en 1766 el índice de subsistencia alcanzó la cifra de 3.05, en lugar de 17.5, lo cual demuestra la importancia del partido para las familias realmonteses. Por esta razón, los mineros de Real del Monte se opusieron violentamente a la supresión del partido que el conde de Regla, Pedro Romero de Terreros, quería realizar en 1766. Durante algunos años de la lucha por la de independencia se van a obtener niveles inferiores a los de subsistencia (véase gráfica 3). En 1766 la familia del barretero podía obtener más de tres veces la canasta de subsistencia, incluidos alimentos, renta, ropa, jabón, velas y combustible.

Desde 1875 se observa una caída pronunciada del nivel de vida de las familias realmonteses, de forma que entre 1878 y 1900 el índice de bienestar promedió 0.89, lo cual significó que los ingresos que se obtenían eran insuficientes para obtener los niveles mínimos para subsistir, es decir que ya en estos años la familia del barretero vivía en situación de extrema pobreza, debido a que sus ingresos no alcanzaban para conseguir las calorías mínimas para sobrevivir. Esta situación se presentó debido a que, a partir de 1875, tal y como se señaló arriba, a los barreteros les comenzaron a cobrar los insumos que utilizaban para desempeñar su trabajo. Dichos insumos representaban 


\section{GRÁFICA 3. ÍNDICE DE SUBSISTENCIA DE UNA FAMILIA REALMONTENSE, $1766-1896$}

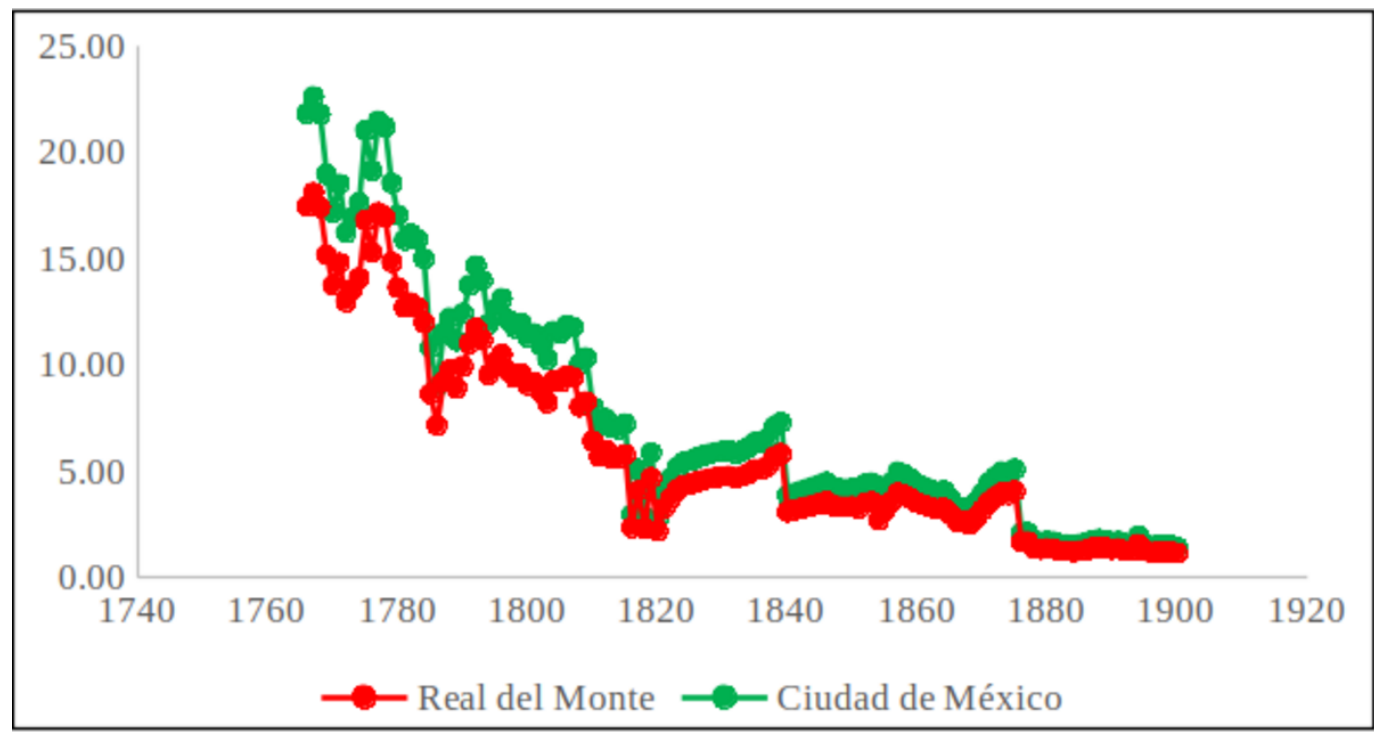

Fuente: elaboración con base en la gráfica 2.

la cuarta parte de sus salarios, por lo que sólo percibían un salario de 37.5 centavos en lugar de los 50 que recibían antes. ${ }^{15}$ En la gráfica 4 se aprecia la diferencia entre los índices de subsistencia con salarios y partido y únicamente con salarios.

Un elemento significativo que afectó de manera importante el índice de los salarios reales fue la inflación, por lo que a continuación se presenta un análisis de ella. En el último cuarto del siglo XviI (1775-1800) la inflación promedio anual fue de 104.9; en el periodo de la insurrección armada por la independencia de México (1810-1821) la tasa fue de 157.7, alcanzando el máximo histórico de 457 en 1816. Entre 1822 y 1862 los precios promediaron 97.3. Durante el segundo imperio (1863-1867) la inflación promedió 114.2, y en 1865 alcanzó la cifra de 231.8. Esta situación llevó al emperador Maximiliano a ordenar que se investigara la causa del incremento de los precios. ${ }^{16}$ De 1867 y hasta 1900 la inflación promedio fue de 107.4 (véase gráfica 5).

\section{Salarios Reales de Real del Monte en RELación con otras CiUdAdes Del Mundo}

A continuación, realizaremos una comparación de índices de bienestar entre Real del Monte y varias regiones del mundo. En la gráfica 6 se observa la superioridad de Real del Monte (con partido) sobre otras regiones europeas entre 1766 y 1814 .

En 1766 el índice de bienestar de Real del Monte era de 17.5, mientras que Ámsterdam tenía un valor de 4.1, seguido de Londres con 3.6. También fue muy superior a Barcelona, Florencia y Austria entre 1766 y 1796 . A partir de 1844 y hasta 1898 Real del Monte fue superado por

${ }^{15}$ Esta evidencia está registrada en los libros de raya de las minas de Real del Monte.

${ }^{16}$ Fondo Ayuntamiento y Gobierno del Distrito Federal, Abasto de Carne, vol. 8, exp. 292, 24 de mayo de 1866. Archivo Histórico de la Ciudad de México (en adelante AHcmx). 


\section{GRÁFICA 4. COMPARACIÓN DE LOS ÍNDICES DE SUBSISTENCIA, CON PARTIDO Y SIN ÉL, DE UNA FAMILIA REALMONTENSE}

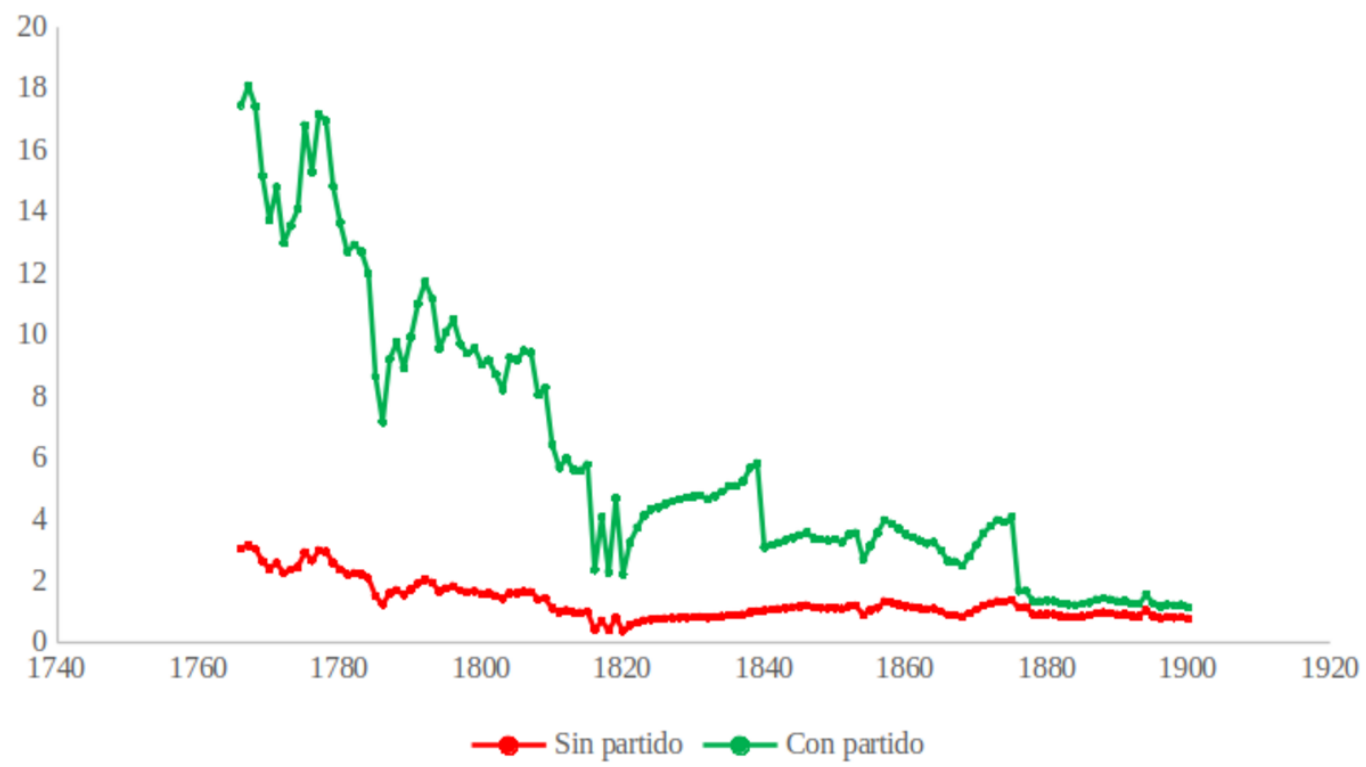

Fuente: elaboración con base en las gráficas 2 y 3 .

GRÁFICA 5. ÍNDICE DE PRECIOS AL CONSUMIDOR DE LA CIUDAD DE MÉXICO

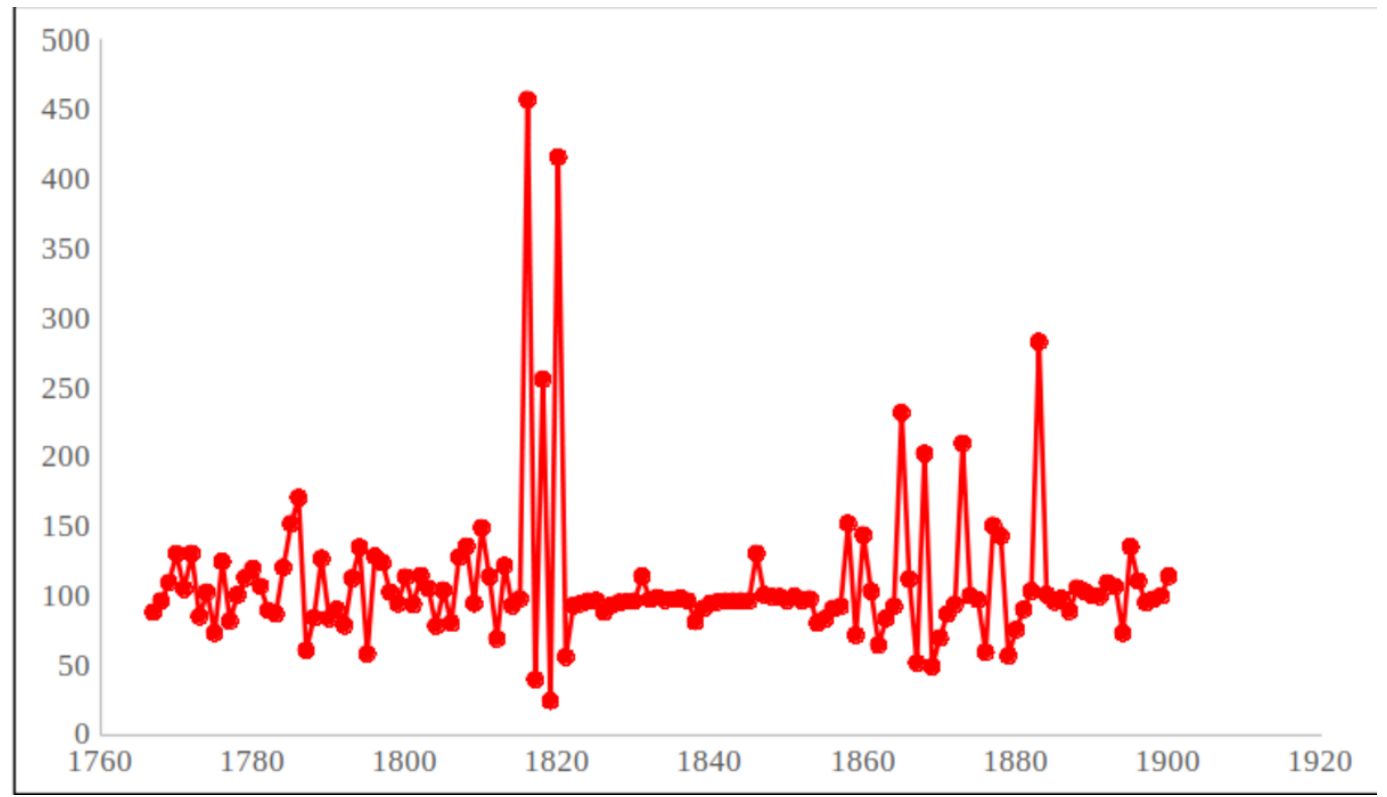

Fuente: elaboración propia con base en la gráfica 1. 


\section{GRÁFICA 6. ÍNDICE DE SALARIOS REALES CON PARTIDO DE REAL DEL MONTE EN COMPARACIÓN CON CIUDADES DE EUROPA, 1766-1898}

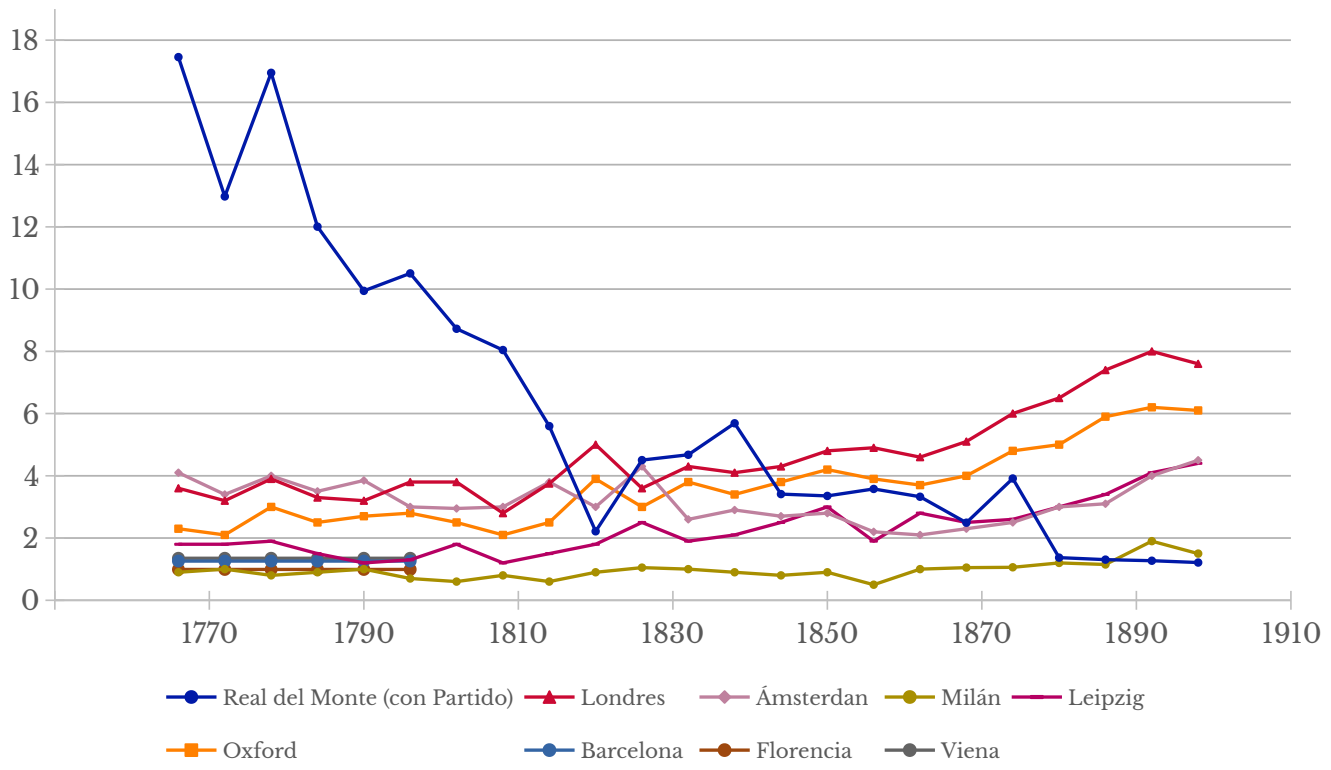

Fuentes: para Real del Monte, véase gráfica 2; para Londres, Oxford, Leipzig, Milán y Ámsterdam, véase Allen et al. (2011). Los salarios corresponden a ocupaciones no calificadas de la industria de la construcción en las ciudades europeas. Para Barcelona, Florencia y Viena, véase Martínez-Galarraga y Prat (2014) con salarios diarios de los trabajadores de la construcción.

Londres y Oxford, y en 1880 por Leipzig. A finales del siglo xix Real del Monte se ubicó en el último lugar respecto a los índices de bienestar de la muestra de países, siendo que en 1766 ocupaba el primero.

En relación con regiones asiáticas y de Venezuela, Real del Monte fue muy superior a ellas entre 1766 y hasta 1892; sin embargo, el índice se fue reduciendo de manera paulatina, pero sin nunca alcanzar niveles por debajo del de subsistencia (véase gráfica 7). Es en 1886 y hasta 1898 que Beijín y San Petersburgo superan a Real del Monte; el índice de bienestar promedio en ese periodo fue $1.57,1.47$ y 1.26 , respectivamente.

Si tomamos en cuenta el salario sin partido, en 1766 los trabajadores de la construcción de Ámsterdam tenían un índice de salarios reales ligeramente superior a los mineros de Real del Monte (véase gráfica 8). En todo nuestro periodo de estudio, excepto entre 1832-1862, Londres y Oxford van a seguir un camino opuesto a Real del Monte, pues mientras el índice de las dos ciudades inglesas se va incrementando, el de Real del Monte va disminuyendo. En Asia, Beijing era la más cercana a Real del Monte en 1766 (véase gráfica 9). El índice de Real del Monte fue superior al de Asia hasta 1874, porque en adelante fue superado por Beijín y San Petersburgo. A partir de 1880 y hasta 1898 Real del Monte alcanzó cifras que estuvieron por debajo de niveles de subsistencia y ya para 1898 todas las regiones asiáticas, junto con Venezuela, superaron en niveles de bienestar a la región minera de México. 


\section{GRÁFICA 7. ÍNDICE DE SALARIOS REALES CON PARTIDO DE REAL DEL MONTE EN COMPARACIÓN CON CIUDADES DE ASIA, 1766-1898}

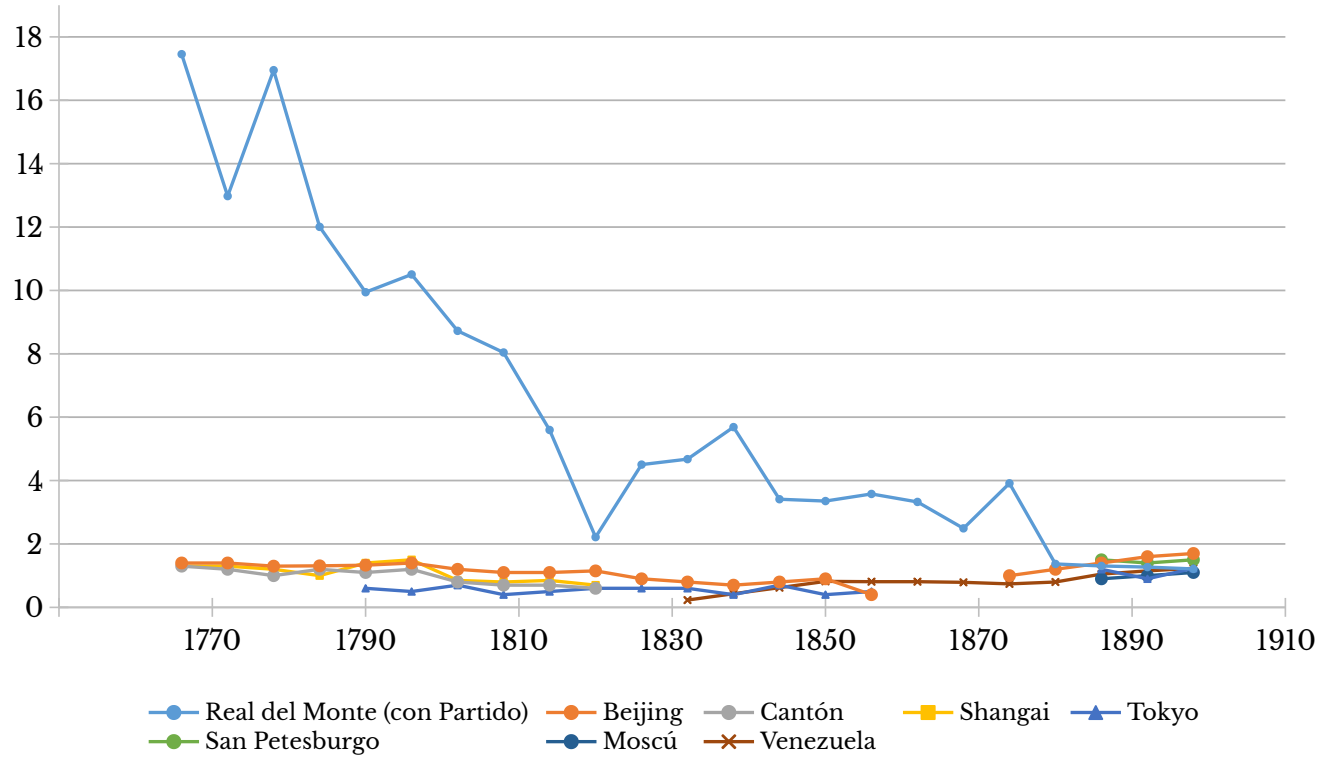

Fuentes: para Real del Monte, véase gráfica 2. Para Beijing, Shanghái, Tokio y Cantón, véase Allen et al. (2011). Para Moscú y San Petersburgo, véase Khaustova (2013); los salarios de estos últimos corresponden a ocupaciones no calificadas en el sector de la construcción y la industria textil. Para Venezuela, véase Arroyo (2013); los salarios corresponden a ocupaciones de baja calificación tales como porteros y sirvientes.

\section{Conclusiones}

Este trabajo presenta una serie de largo plazo (de 1766 a 1900) de los salarios de los barreteros, el oficio más numeroso y uno de los más importantes al interior de las minas. Algunos autores han señalado que los trabajadores mineros en general -no sólo los barreteros- eran bien pagados, al grado de señalarlos como la aristocracia del trabajo o la elite trabajadora. Sin embargo, un primer análisis nos llevó a concluir que los barreteros no entraban en esa categoría.

El salario de los trabajadores de elite fluctuaba entre 300 o 400 centavos, y lo ganaban maquinistas, mecánicos, motoristas y electricistas. El salario de los barreteros se mantuvo inalterable durante 134 años en 50 centavos al día. Pero además de los salarios, los barreteros recibían ingresos extraordinarios a través del partido. Sumando salario y partido podían obtener 400 centavos: 350 centavos del partido más 50 de su salario, ingresos con los que ya entraban en la categoría de elite trabajadora.

Se ha podido demostrar que el componente central de la remuneración de los barreteros no era el salario monetario, sino el partido, es decir, el mineral que ellos mismos podían extraer y comercializar una vez concluida su jornada como asalariados. Lo que explica la revuelta de 1766. 


\section{GRÁFICA 8. ÍNDICE DE SALARIOS REALES SIN PARTIDO DE REAL DEL MONTE EN COMPARACIÓN CON EUROPA}

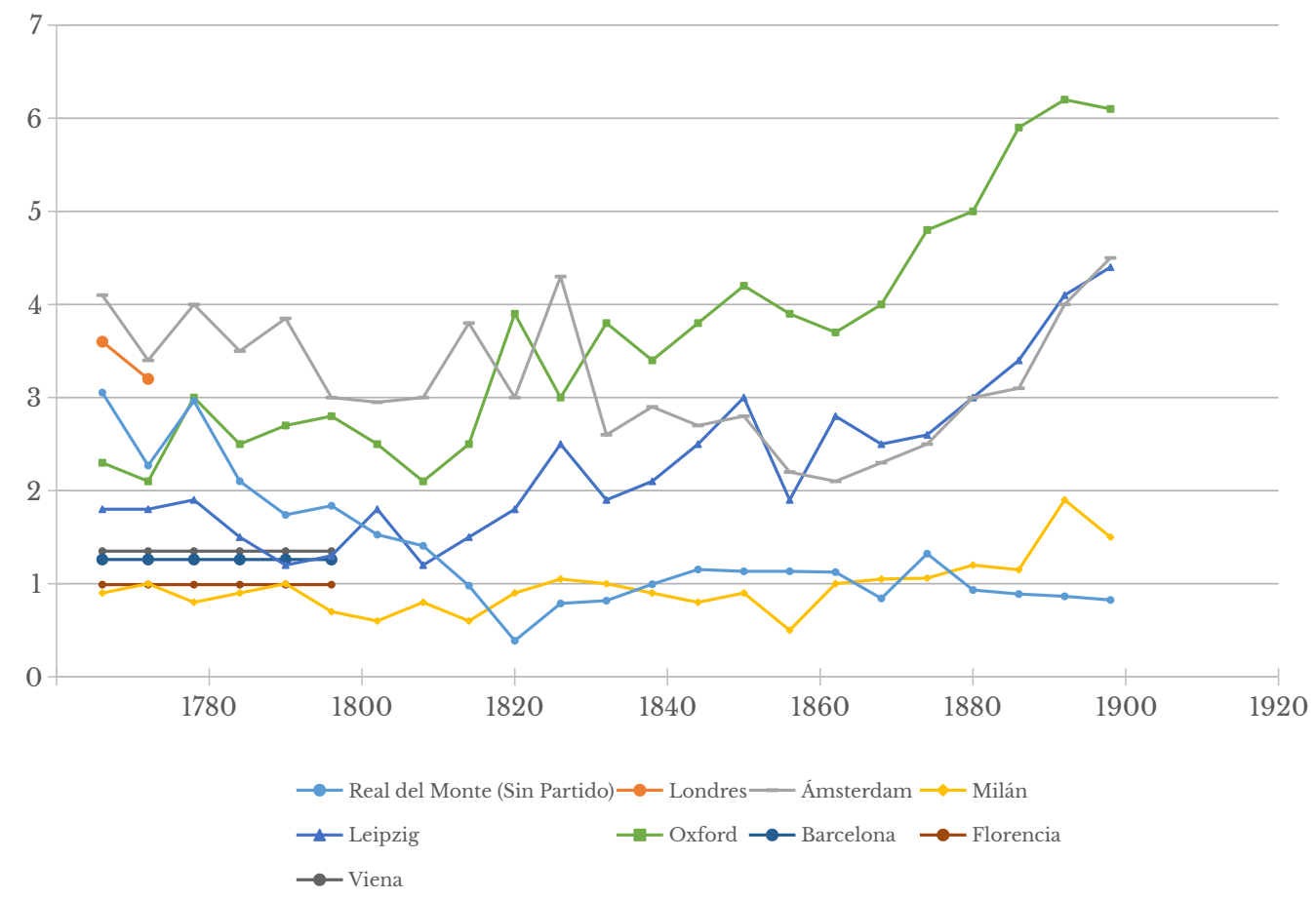

Fuente: elaboración propia con base en las gráficas 2 y 6 .

A nivel internacional los salarios reales con partido de los mineros de Real del Monte fueron superiores a ciudades europeas: Ámsterdam, Barcelona, Florencia, Leipzig, Londres, y Viena, hasta antes del movimiento de independencia. Respecto a las ciudades asiáticas, la supremacía de Real del Monte perduró hasta finales del siglo xix (1880-1900).

Una de las razones por las que los salarios reales, con partido, fueron altos antes de 1810, en relación con el periodo restante, se debió básicamente a cuatro factores: $a$ ) los precios de los productos se incrementaron durante la guerra de independencia, mientras que los salarios permanecieron constantes; $b$ ) la desaparición del partido entre 1840 y hasta 1874 , periodo durante el cual estuvo vigente la forma de pago por destajo, a través de la cual, en promedio, se obtenían menos ingresos que por el partido; $c$ ) al reinstaurarse el partido en 1875 los ingresos que se percibían por tal concepto eran menores a los percibidos durante el periodo novohispano, mientras los precios seguían incrementándose, los salarios permanecían fijos, sólo que los 50 centavos que percibían tenían que pagar la cuarta parte por los insumos que obtenían, lo que resultaba en un salario bruto de 37.5 centavos, y $d$ ) la voluntad política de no incrementar los salarios de los trabajadores al mismo ritmo que la inflación para no afectar el bienestar de los trabajadores y de sus familias. 


\section{GRÁFICA 9. ÍNDICE DE SALARIOS REALES SIN PARTIDO DE REAL DEL MONTE, EN COMPARAGIÓN CON CIUDADES, 1766-1898}

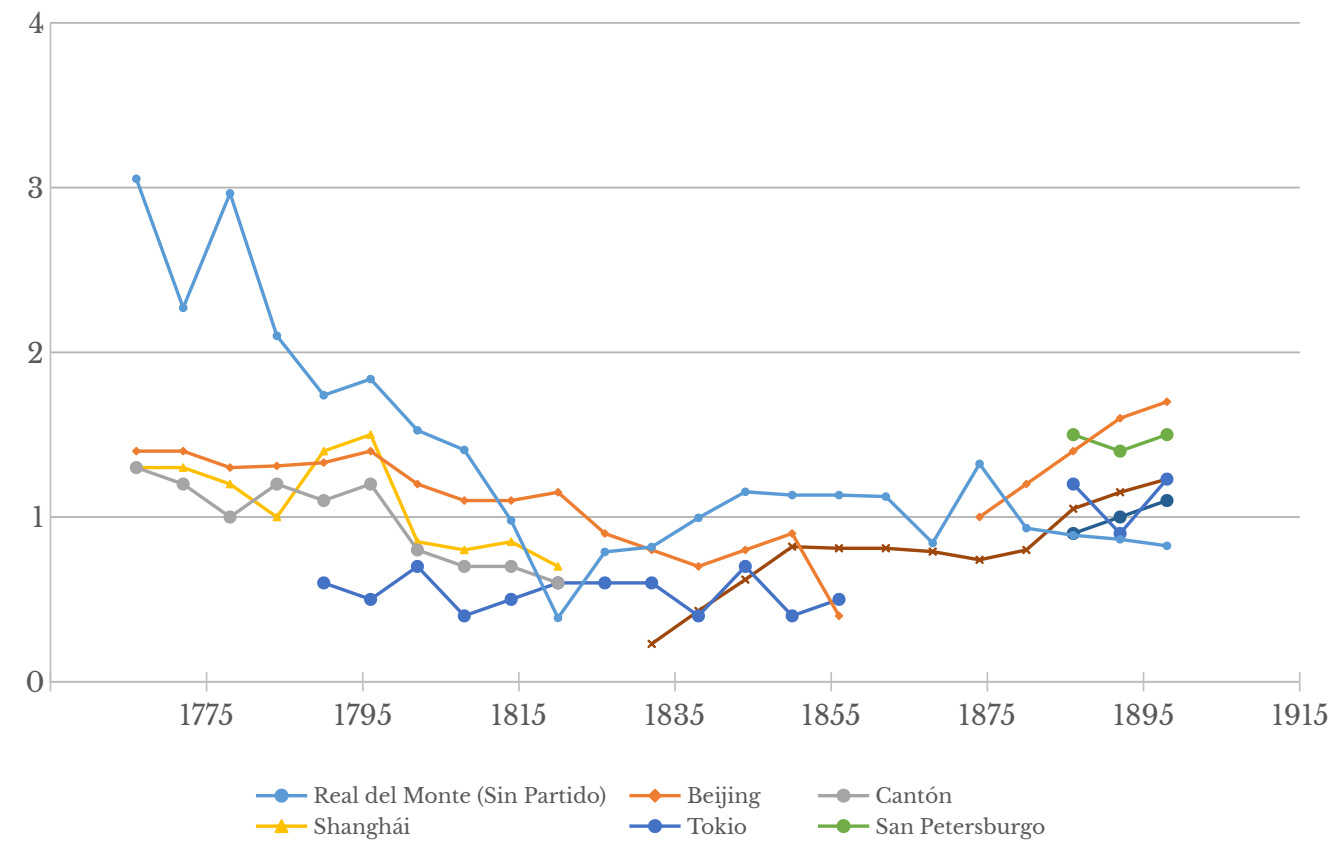

Fuente: elaboración propia con base en las gráficas 3 y 7 .

Sin duda alguna, la labor más complicada de este artículo fue la recopilación de datos del precio de once bienes: maíz, frijol, carne de res, manteca, pan, azúcar, sal y café, velas, jabón y carbón, todo para los años entre 1766 y 1900. Con estos precios se elaboró una canasta de bienes de subsistencia, la cual, sin duda, es uno de los principales resultados y aportaciones. Con la canasta se calculó un índice de precios al consumidor, con año base en 1766, y con él hemos deflactado los salarios nominales y hemos obtenido la serie de salarios reales. Al hacerlo hemos encontrado incrementos de precios muy elevados, que indudablemente mermaron la capacidad adquisitiva de los trabajadores.

Esta situación se vio reflejada con el índice de salarios reales de una familia minera realmontense, incluyendo los salarios del jefe de familia y de un hijo. No pudimos tomar en cuenta los de las mujeres por falta de datos y otras razones que hemos explicado. El índice de subsistencia con partido en 1766 fue casi 18 veces más a lo rigurosamente necesario para sobrevivir. A partir de ese año comenzó a descender de manera paulatina, con altibajos, hasta llegar a la cifra de 1.15 en 1900. Esta cantidad estuvo ligeramente superior a los niveles de subsistencia. Sin tomar en cuenta el partido, en 1766 el índice de salarios reales fue de 3.05 y descendió a niveles inferiores a los de subsistencia, con una cifra de 0.89 en promedio entre 1878 y 1900, lo cual significó que la familia no podía comprar lo mínimo para sobrevivir. 


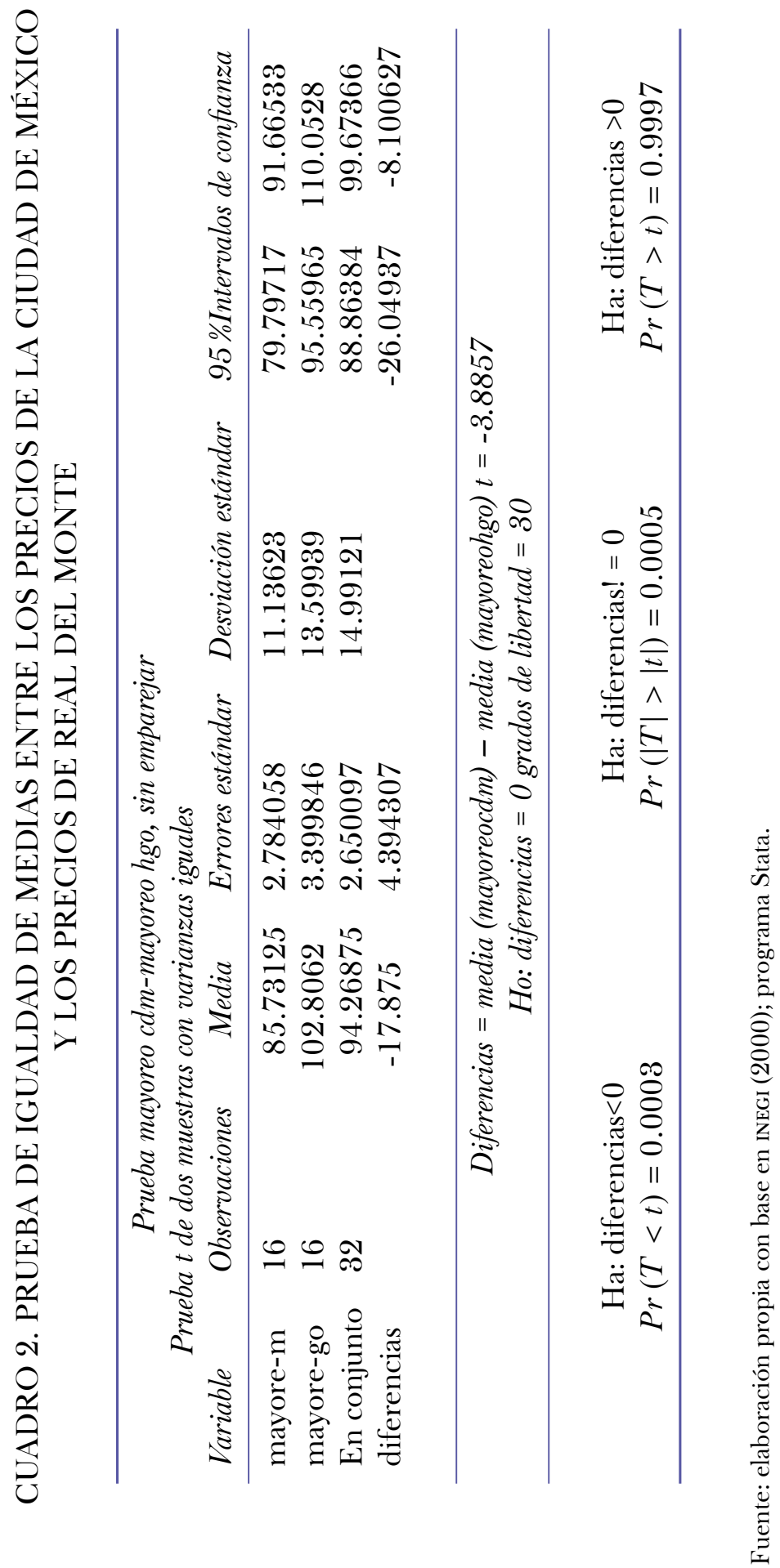




\section{ANEXo 1}

Indices de precios de Real del Monte, Hidalgo, y su relación con el índice de precios de la ciudad de México para el periodo 1766-1900

En la actualidad Real del Monte o Mineral del Monte es un municipio del actual estado de Hidalgo, por lo tanto, nos referiremos a Hidalgo como si fuera Real del Monte. El estado de Hidalgo se creó en 1869, no obstante, se dispone de precios de cuatro productos a partir de 1885 y hasta 1900: azúcar, carne, maíz y frijol; con base en ellos fue calculado el índice de precios de Laspeyres (IPLRM 1885-1900). Asimismo, se tiene una serie de precios del periodo 1766-1900 para ocho productos alimenticios vendidos en la ciudad de México: maíz, frijol, carne, manteca, pan, azúcar, sal y café. Con ellos fue construido un índice de precios de Laspeyres (IPLCDM 1776-1900).

Se construyó un índice de precios de la ciudad de México (IPLCDM 1885-1900) con los mismos productos que se tienen para el de Real del Monte, solamente para los años entre 1885 y 1900 . Ello, a fin de conocer si estadísticamente son iguales mediante pruebas que consideraban si se distribuyen como una normal, si sus varianzas son iguales y si sus medias son iguales. En el cuadro 2 se presentan los resultados sobre la igualdad de medias y encontramos que los precios de Real del Monte (con media 102.80 en el periodo referido) son superiores estadísticamente a los precios de la ciudad de México (85.73), con la hipótesis nula siguiente:

$$
\left.H_{0}: \text { mean }(\text { mayoreocdm })-\text { mean (mayoreohgo }\right) \leq 0
$$

Y con la hipótesis alternativa

$$
H_{1}: \text { mean }(\text { mayoreocdm })-\text { mean }(\text { mayoreohgo })>0
$$

En este caso, el valor de probabilidad es alto, y no se rechaza la hipótesis nula referida antes.

Estas pruebas para comparar si las distribuciones de estos índices de Real del Monte y de la ciudad de México del periodo 1885-1900 son iguales también se hicieron con el método intensivo en cómputo bootstrap, con la hipótesis nula de que son iguales. La conclusión es que el índice de precios de Real del Monte es diferente del índice de precios de la Ciudad de México, al ser el valor de probabilidad muy bajo, menor que 0.05 (véase cuadro 3).

GUADRO 3. IGUALDAD DE LAS MEDIAS DEL ÍNDICE DE PRECIOS DE LASPEYRES DE LA GIUDAD DE MÉXICO (IPLCDM) CON EL ÍNDICE DE PRECIOS DE

\begin{tabular}{|c|c|c|c|c|c|c|}
\hline & Valor observado & $\begin{array}{c}\text { Bootstrap } \\
\text { (método de remuestreo) }\end{array}$ & & & \multicolumn{2}{|c|}{ Basada en normal } \\
\hline & Coeficiente & Error estándar & $z$ & $P>|z|$ & 95\% Confianza & Intervalo \\
\hline $\mathrm{t}$ & -3.885709 & 1.018 & -3.82 & 0 & -5.880952 & -1.890467 \\
\hline
\end{tabular}
LASPEYRES DE REAL DEL MONTE (IPLRM), 1885-1900

Fuente: elaboración propia con base en INEGI (2000); programa Stata.

Un objetivo ulterior es definir un modelo sobre la relación entre el IPLRM del periodo 18851900 respecto a los últimos 16 datos del IPCDM 1776-1900. Para ello primero se determinó si a estas variables, en esos años, se les puede considerar como estacionarias, para lo cual se determi- 
nó el componente determinístico (tendencia e intercepto, sólo intercepto, ninguno) que debía ser incorporado en la regresión respectiva, mediante el contraste $\Phi_{i}$ de regresiones restringidas y no restringidas; ambas fueron estacionarias (véanse cuadros 4,5 y 6 ).

\section{GUADRO 4. ECUACIÓN DICKEY-FULLER AUMENTADA CON INTERCEPTO PARA LA SERIE IPLCD 1885-1900, CON UNA DIFERENCIA REZAGADA}

\begin{tabular}{|c|c|c|}
\hline \multicolumn{2}{|c|}{ Componentes } & Conclusión \\
\hline $\begin{array}{c}H_{0}: \text { coef } \text {.tendencia }=0 \\
\text { Estadístico } \\
\text { calculado } F_{3} \\
9.56\end{array}$ & $\begin{array}{c}H_{1}: \text { coef } \text {.tendencia } \neq 0 \\
\text { Estadístico } \\
\text { crítico } \Phi_{3} \\
6.49\end{array}$ & $\begin{array}{l}\text { Con intercepto } \\
\text { y tendencia }\end{array}$ \\
\hline $\begin{array}{c}H_{0}: \text { Raíz unitaria } \\
\text { (serie no estacionaria) } \\
\text { Prueba de Dickey-Fuller } \\
\text { Aumentada }\end{array}$ & $\begin{array}{l}H_{1} \text { : Raíz no unitaria } \\
\quad \text { (serie estacionaria) } \\
\text { Estadístico Mackinnon } \\
\text { a } 5 \% \text { de significancia }\end{array}$ & \\
\hline$|-3.786|$ & 3.60 & $\begin{array}{l}\text { Raíz no unitaria, } \\
\text { serie estacionaria }\end{array}$ \\
\hline
\end{tabular}

Fuente: elaboración propia con base en INEGI (2000); programa Eviews.

CUADRO 5. ECUACIÓN DICKEY-FULLER AUMENTADA SIN INTERCEPTO NI TENDENCIA PARA LA SERIE IPLRM 1885-1900, SIN UNA DIFERENCIA REZAGADA

\begin{tabular}{|c|c|c|}
\hline \multicolumn{2}{|c|}{ Componentes } & Conclusión \\
\hline $\begin{array}{c}H_{0}: \text { coef } \text {.intercepto }=0 \\
\text { Estadístico } \\
\text { calculado } F_{1} \\
6.10\end{array}$ & $\begin{array}{c}H_{1}: \text { coef.intercepto } \neq 0 \\
\text { Estadístico } \\
\text { crítico } \Phi_{1} \\
4.71\end{array}$ & $\begin{array}{l}\text { Con intercepto } \\
\text { sin tendencia }\end{array}$ \\
\hline $\begin{array}{c}H_{0} \text { : Raíz unitaria } \\
\text { (serie no estacionaria) } \\
\text { Prueba de Dickey-Fuller } \\
\text { Aumentada }\end{array}$ & $\begin{array}{c}H_{1} \text { : Raíz no unitaria } \\
\text { (serie estacionaria) } \\
\text { Estadístico Mackinnon } \\
\text { a } 5 \% \text { de significancia }\end{array}$ & \\
\hline$|-2.47|$ & $|-1.71|$ & $\begin{array}{l}\text { Raíz no unitaria, } \\
\text { serie estacionaria }\end{array}$ \\
\hline
\end{tabular}

Fuente: véase cuadro 4. 


\section{CUADRO 6. MODELO DE REGRESIÓN DE MÍNIMOS CUADRADOS ORDINARIOS CON CORRECGIÓN DE PRAIS-WINSTEN}

\begin{tabular}{|c|c|c|c|c|c|c|}
\hline Fuente & $S S$ & $d f$ & $M S$ & Número de observaciones & $=$ & 15 \\
\hline & & & & $\mathrm{F}(1,14)$ & $=$ & 198.66 \\
\hline Modelo & 4.43874973 & 1 & 4.4367497 & Prob $>\mathrm{F}$ & $=$ & 0 \\
\hline \multirow[t]{2}{*}{ Residual } & 0.31280543 & 14 & 0.0223432 & R-cuadrado & $=$ & 0.9342 \\
\hline & & & & R-cuadrado ajustado & $=$ & 0.9295 \\
\hline Total & 4.75155516 & 15 & 0.3167703 & Root MSE & $=$ & 0.14948 \\
\hline Coeficiente & Error estándar & $t$ & $p>|t|$ & $95 \%$ Intervalo & & Confianza \\
\hline $\begin{array}{c}1.212752 \\
0.4721093\end{array}$ & 0.0860429 & 14.09 & 0 & 1.028209 & & 1.397296 \\
\hline Estadístico I & urbin-Watson ( & riginal) & & 1.083781 & & \\
\hline Estadístico I & urbin-Watson ( & ransforn & nado) & 2.248469 & & \\
\hline
\end{tabular}

Fuente: véase cuadro 4.

Fue establecida una relación econométrica con la variable dependiente el ÍPLRM 1885-1900 respecto al IPLCDM 1885-1900, estimada mediante mínimos cuadrados ordinarios, misma que incumplió con el supuesto de autocorrelación, pero se realizó la corrección de Prais-Winster, que llevó a la siguiente relación econométrica.

Se estimaron los residuales de la anterior regresión para determinar si son estacionarios, y efectivamente lo son (véase cuadro 7).

CUADRO 7. EGUACIÓN DICKEY-FULLER AUMENTADA SIN INTERCEPTO NI TENDENCIA PARA LA SERIE DE RESIDUOS...

\begin{tabular}{|c|c|c|}
\hline \multicolumn{2}{|c|}{ Componentes } & Conclusión \\
\hline $\begin{array}{c}H_{0}: \text { coef } \text {.intercepto }=0 \\
\text { Estadístico } \\
\text { calculado } F_{1} \\
0.18\end{array}$ & $\begin{array}{c}H_{1}: \text { coef.intercepto } \neq 0 \\
\text { Estadístico } \\
\text { crítico } \Phi_{1} \\
4.71\end{array}$ & $\begin{array}{l}\text { Sin intercepto } \\
\text { ni tendencia }\end{array}$ \\
\hline $\begin{array}{c}H_{0} \text { : Raíz unitaria } \\
\text { (serie no estacionaria) } \\
\text { Prueba de Dickey-Fuller } \\
\text { Aumentada }\end{array}$ & $\begin{array}{c}H_{1} \text { : Raíz no unitaria } \\
\text { (serie estacionaria) } \\
\text { Estadístico Mackinnon } \\
\text { a } 5 \% \text { de significancia }\end{array}$ & \\
\hline$|-2.09|$ & $|-1.95|$ & $\begin{array}{l}\text { Raíz no unitaria, } \\
\text { serie estacionaria }\end{array}$ \\
\hline
\end{tabular}

Fuente: véase cuadro 4. 
CUADRO 8. ÍNDICE DE PRECIOS DE LASPEYRES DE LA CIUDAD DE MÉXICO (IPLCDM), 1766-1900, 1900=1

\begin{tabular}{|c|c|c|c|c|c|c|c|}
\hline Año & $\begin{array}{c}\text { IPLCDM } \\
1766-1900\end{array}$ & Año & $\begin{array}{c}\text { IPLCDM } \\
1766-1900\end{array}$ & Año & $\begin{array}{c}\text { IPLCDM } \\
\text { 1766-1900 }\end{array}$ & Año & $\begin{array}{c}\text { IPLCDM } \\
1766-1900\end{array}$ \\
\hline 1766 & 0.288431 & 1800 & 0.608472 & 1834 & 1.45606 & 1868 & 1.05073 \\
\hline 1767 & 0.253759 & 1801 & 0.568323 & 1835 & 1.41351 & 1869 & 0.512104 \\
\hline 1768 & 0.244013 & 1802 & 0.649406 & 1836 & 1.38842 & 1870 & 0.355171 \\
\hline 1769 & 0.266471 & 1803 & 0.683834 & 1837 & 1.33591 & 1871 & 0.307649 \\
\hline 1770 & 0.346824 & 1804 & 0.533519 & 1838 & 1.08356 & 1872 & 0.288295 \\
\hline 1771 & 0.363154 & 1805 & 0.554325 & 1839 & 0.982197 & 1873 & 0.604415 \\
\hline 1772 & 0.473189 & 1806 & 0.443636 & 1840 & 0.926511 & 1874 & 0.603335 \\
\hline 1773 & 0.40139 & 1807 & 0.566162 & 1841 & 0.885406 & 1875 & 0.585548 \\
\hline 1774 & 0.411293 & 1808 & 0.766984 & 1842 & 0.849642 & 1876 & 0.3466 \\
\hline 1775 & 0.300588 & 1809 & 0.723138 & 1843 & 0.816442 & 1877 & 0.521701 \\
\hline 1776 & 0.37459 & 1810 & 1.07646 & 1844 & 0.784946 & 1878 & 0.745693 \\
\hline 1777 & 0.306147 & 1811 & 1.22344 & 1845 & 0.754858 & 1879 & 0.422846 \\
\hline 1778 & 0.307716 & 1812 & 0.841525 & 1846 & 0.984076 & 1880 & 0.318703 \\
\hline 1779 & 0.3467 & 1813 & 1.02195 & 1847 & 0.989899 & 1881 & 0.286866 \\
\hline 1780 & 0.413827 & 1814 & 0.9476 & 1848 & 0.982613 & 1882 & 0.29618 \\
\hline 1781 & 0.441317 & 1815 & 0.924994 & 1849 & 0.973077 & 1883 & 0.838184 \\
\hline 1782 & 0.393729 & 1816 & 4.2324 & 1850 & 0.939308 & 1884 & 0.844405 \\
\hline 1783 & 0.341671 & 1817 & 1.66756 & 1851 & 0.934839 & 1885 & 0.806142 \\
\hline 1784 & 0.410769 & 1818 & 4.26769 & 1852 & 0.90081 & 1886 & 0.789323 \\
\hline 1785 & 0.623456 & 1819 & 1.03055 & 1853 & 0.878199 & 1887 & 0.699949 \\
\hline 1786 & 1.06316 & 1820 & 4.2873 & 1854 & 0.703737 & 1888 & 0.737417 \\
\hline 1787 & 0.641493 & 1821 & 2.3904 & 1855 & 0.585895 & 1889 & 0.759327 \\
\hline 1788 & 0.538273 & 1822 & 2.21749 & 1856 & 0.530729 & 1890 & 0.759168 \\
\hline 1789 & 0.682074 & 1823 & 2.09029 & 1857 & 0.488404 & 1891 & 0.754946 \\
\hline 1790 & 0.569051 & 1824 & 2.00723 & 1858 & 0.742457 & 1892 & 0.82367 \\
\hline 1791 & 0.511324 & 1825 & 1.9356 & 1859 & 0.530751 & 1893 & 0.877298 \\
\hline 1792 & 0.400354 & 1826 & 1.70065 & 1860 & 0.762955 & 1894 & 0.639648 \\
\hline 1793 & 0.449982 & 1827 & 1.58155 & 1861 & 0.785764 & 1895 & 0.865055 \\
\hline 1794 & 0.606626 & 1828 & 1.50211 & 1862 & 0.504496 & 1896 & 0.954146 \\
\hline 1795 & 0.351788 & 1829 & 1.43733 & 1863 & 0.42211 & 1897 & 0.905658 \\
\hline 1796 & 0.45138 & 1830 & 1.37901 & 1864 & 0.389437 & 1898 & 0.88039 \\
\hline 1797 & 0.557585 & 1831 & 1.572 & 1865 & 0.902654 & 1899 & 0.877665 \\
\hline 1798 & 0.57045 & 1832 & 1.5275 & 1866 & 1.01041 & 1900 & 1 \\
\hline 1799 & 0.537124 & 1833 & 1.50478 & 1867 & 0.519355 & - & - \\
\hline
\end{tabular}

Fuente: véase cuadro 4.

Se determinó si los datos del IPLCDM 1766-1900 (véase cuadro 8) son estacionarios con la prueba de Clemente, Montañés y Reyes con dos rompimientos estructurales. Se encontró que era estacionaria (véase Anexo 2). 
Anexo 2

CUADRO 9. FUENTES DE DATOS DE LOS PRECIOS

\begin{tabular}{|c|c|c|}
\hline Archivo & Fuente & $\begin{array}{l}\text { Años o series de datos } \\
\text { proporcionados }\end{array}$ \\
\hline \multicolumn{3}{|c|}{ Carnes de res } \\
\hline- & Quiroz (2005) & $\begin{array}{l}1766-1768,1771- \\
1773,1781-1783\end{array}$ \\
\hline- & Gaceta de México, 14 de enero de 1784 & 1784 \\
\hline AHSS & $\begin{array}{l}\text { Fondos de Establecimientos Hospitalarios y Asistenciales, Hos- } \\
\text { pitales y Hospicios, Hospicio de Pobres, libro } 3\end{array}$ & $1774-1777$ \\
\hline AHCMX & Bandos, caja 92, f. 1 , año 1811 & 1811 \\
\hline AHSS & $\begin{array}{l}\text { Establecimientos Hospitalarios y Asistenciales, Casa de Niños } \\
\text { Expósitos, Administración, libros } 7 \text { y } 14\end{array}$ & $\begin{array}{l}1812-1825 ; 1831- \\
1837\end{array}$ \\
\hline \multirow[t]{3}{*}{ AHCMX } & Contratas, vol. 560 , exp. 13 & 1858 \\
\hline & Beneficencia Pública, Hospital de San Hipólito, leg. 8, exp. 8. & 1860 \\
\hline & $\begin{array}{l}\text { Beneficencia Pública, Establecimientos Hospitalarios, Hospital } \\
\text { de San Hipólito, leg. 1, exps. 5, 13, } 20\end{array}$ & $1861,1865,1866$ \\
\hline AHSS & $\begin{array}{l}\text { Establecimientos Hospitalarios y Asistenciales, Hospitales y } \\
\text { Hospicios, Hospital del Divino Salvador, libro } 3\end{array}$ & 1873 \\
\hline \multirow[t]{2}{*}{ AHCMX } & Contratas, vol. 560, exp. 14, año 1867-1875 & 1875 \\
\hline & $\begin{array}{l}\text { Beneficencia Pública, Establecimientos Asistenciales, Hospital } \\
\text { de San Hipólito, leg. 5, exp. } 7\end{array}$ & 1877 \\
\hline AHSS & $\begin{array}{l}\text { Beneficencia Pública, Establecimientos Hospitalarios, Hospital } \\
\text { del Divino Salvador, leg. } 12 \text {, exp. } 9\end{array}$ & 1878 \\
\hline AHSS & $\begin{array}{l}\text { Beneficencia Pública, Abastecimiento, Proveeduría, leg. 1, exp. } \\
17\end{array}$ & 1883-1884 \\
\hline AGEH & Tula, Gobierno, Hacienda, caja 147 & 1885 \\
\hline- & $\begin{array}{l}\text { Instituto Nacional de Estadística, Geografía e Informática } \\
(2000)\end{array}$ & $1886-1900$ \\
\hline \multicolumn{3}{|c|}{ Maiz } \\
\hline- & Canudas (2005) & 1867 \\
\hline- & Challú y Gómez-Galvarriato (2015) & $1825,1850,1860$ \\
\hline- & Estadística Mercantil, 25 de marzo de 1858, p. 15 & 1856 \\
\hline- & Garner (2003, pp. 691-693) & $\begin{array}{l}1776-1815,1817 \\
1819\end{array}$ \\
\hline- & $\begin{array}{l}\text { Instituto Nacional de Estadística, Geografía e Informática } \\
\text { (2000). }\end{array}$ & $\begin{array}{l}1877-1884,1886- \\
1900\end{array}$ \\
\hline AHSS & $\begin{array}{l}\text { Fondos de Establecimientos Hospitalarios y Asistenciales Hos- } \\
\text { pitales y Hospicios, Hospital de San Hipólito, libro } 10\end{array}$ & 1841 \\
\hline
\end{tabular}


Establecimientos Hospitalarios y Asistenciales, Hospitales y 1873 Hospicios, Hospital del Divino Salvador, libro 3

AGEH Tula, Gobierno, Hacienda, exp. 3, caja 147

Pan

- $\quad$ García (1989, p. 76)

- $\quad$ Gaceta de México, 14 de enero de 1784

Establecimientos Hospitalarios y Asistenciales, Hospitales y Hospicios, Hospicio de Pobres, libros 3-7

AHSS

Fondos de Establecimientos Hospitalarios y Asistenciales, Casa de Niños Expósitos. Administración, libros 7, 8, 14, 20, 47 y 53

Real audiencia: Fiel Ejecutoria, Panaderías, Manifestaciones de

AHCMx Trigo, vol. 3830, exps. 168, 192, 193

Cárceles contratas, archivos 11 y 12

Cárceles contratas, exp. 16

AHss Establecimientos Hospitalarios y Asistenciales, Establecimien-

tos Hospitalarios, Hospital del Divino Salvador, leg. 11, exps. 2 y 25

AHCMx Policía en General, exps. 640, 742

AHss Fondos de Establecimientos Hospitalarios y Asistenciales, Esta-

blecimientos Hospitalarios, Hospital de San Andrés, leg. 6, exp.

34 y leg. 5, exp. 35
1885

1781,1783

1784

$1774-1778$

$1778 ; 1794-1795$, 1798-1808; $1813-$

$1825 ; 1831-1837$, $1846-1847$; $1848-$

$1853 ; 1881-1883$

$1886-1887$

$1810-1812$

1854,1857

1865

1868,1877

1871,1875

$1889 ; 1891-1900$

\section{Manteca}

Establecimientos Hospitalarios y Asistenciales, Hospitales y 1774-1778

AHSS Hospicios, Hospicio de Pobres, libros 3-7

Fondos de Establecimientos Hospitalarios y Asistenciales, Casa 1788-1814, 1824-

de Niños Expósitos, Administración, libros 7, 14, 53

$1825,1831-1837$;

$1846-1851 ; 1882-$

1883

AHPM ML31B-ML35B, ML67B, ML36B- ML38B

$1815-1823$

Beneficencia Pública, Establecimientos Hospitalarios, Hospital 1845

AHss del Divino Salvador, leg. 1, exp. 4

Beneficencia Pública, Establecimientos Hospitalarios, Hospital 1861, 1866

de San Hipólito, leg. 1, exps. 4 y 20

AGEH Tula, Gobierno, Hacienda, exp. 12, caja 108 y exp. 3, cajas $147 \quad 1871,1887,1900$ y 199

- $\quad$ Sánchez (1991) 1875

Beneficencia Pública, Establecimientos Asistenciales, Hospicio 1877

Ahss de Pobres, leg. 5, exp. 7 
Beneficencia Pública, Establecimientos Asistenciales, Casa de 1889, 1893 Niños Expósitos, leg 1, exp. 7 y leg. 3, exp. 12

\section{Azúcar}

Fondos de Establecimientos Hospitalarios y Asistenciales, Hos- 1775-1778

AHSS pitales y Hospicios Hospicio de Pobres, libros 4-7

Beneficencia Pública, Establecimientos Asistenciales, Casa de 1778-1802; 1803-

Niños Expósitos, Administración, libros 7, 8, 14, 43, 45, 53, 1814; 1846-1853;

\section{4}

AHPM ML31B-ML38B

Fondos de Establecimientos Hospitalarios y Asistenciales, Hos-

pitales y Hospicios, Hospicio de Terceros, leg. 1, exp. 12

Beneficencia Pública, Establecimientos Hospitalarios, Hospital

de San Hipólito, leg. 1, exp. 20 y leg 5, exp. 35

AGEH Tula, Gobierno, Hacienda, exp. 12, caja 108

Beneficencia Pública, Establecimientos Asistenciales, Hospicio

de Pobres, leg. 5, exp. 7

ahss Beneficencia Pública, Hospicio de Pobres, libro 24

Beneficencia Pública, Establecimientos Asistenciales Casa de

Niños Expósitos, leg. 1, exp. 7 y leg. 3, exp. 8

- $\quad$ Estadística Mercantil, 25 de marzo de 1858, p. 15

- $\quad$ Estadística Mercantil, 25 de marzo de 1878, p. 15

\section{Sal}

AHSS

Fondos de Instituciones Gubernamentales de Salud o Asisten-

cia, Hospitales y Hospicios, Hospicio de Pobres, libros 4-6

ML13B-ML28B, 1814-1816, ML35B-ML36B, ML38B

AHPM

Fondos Eclesiásticos, Congregación San Pedro, libro 128

Beneficencia Pública, Establecimientos Asistenciales Casa de

Niños Expósitos, libros 14, 43, 53

AHSS Establecimientos Hospitalarios y Asistenciales, Hospitales y

Hospicios. Hospital de Terceros, exp. 12

Beneficencia Pública, Establecimientos Hospitalarios, Hospital

de San Hipólito, leg. 1, exp. 4

AHCMX

Ayuntamiento y Gobierno del Distrito Federal, Abasto de Carne, vol. 8, exp. 292 AHss $\quad$ Beneficencia Pública, Establecimientos Hospitalarios, Hospital
del Divino Salvador, leg. 10, exp. 27

AGEH Tula, Gobierno, Hacienda, exp. 12, caja 108, y exp. 3, cajas 147 y 199

Beneficencia Pública, Establecimientos Asistenciales, Hospicio de Pobres, exp. 7
$1880-1883$

1815-1823

1860

1866,1885

1871

1877

1887

1889,1900

1858

1878
1775-1777

1798-1812, 18141816, 1819-1821, 1823

1822

1846-1853; 1880;

1882-1883

1860

1861

1866

1868

$1871,1885,1900$

1877

AHSS 
Beneficencia Pública, Establecimientos Asistenciales, Casa de 1889 los Niños Expósitos, leg. 1, exp. 7

Establecimientos Asistenciales Casa de Niños Expósitos, leg. 3, 1893 exp. 8

\section{Frijol}

\begin{tabular}{|c|c|c|}
\hline AHSS & Establecimientos Hospitalarios, Hospicio de Pobres, libro 3 & $1766-1774$ \\
\hline \multirow[t]{2}{*}{ AHPM } & $\begin{array}{l}\text { ML13B-ML19B, ML21B-ML22B, ML24B, Caja de 1810, t. } \\
149 \text { exp. 5, ML26B, ML28B- ML35B, ML67B, ML36B }\end{array}$ & $\begin{array}{l}1798-1804,1806- \\
1807,1809,1810 \\
1811-1819,1820 \\
1821\end{array}$ \\
\hline & $\begin{array}{l}\text { Establecimientos Hospitalarios, Hospital de San Hipólito, leg. } \\
\text { 1, exp. } 11\end{array}$ & 1845 \\
\hline AHSS & $\begin{array}{l}\text { Casa de Niños Expósitos, Administración, libros 14, 20, 43, 45, } \\
53\end{array}$ & $\begin{array}{l}1846-1847,1848- \\
1853,1880-1883\end{array}$ \\
\hline- & Estadística Mercantil, 25 de marzo de 1858, p. 15 & 1858 \\
\hline AHCMX & $\begin{array}{l}\text { Fondo Ayuntamiento y Gobierno del Distrito Federal, Abasto } \\
\text { de carne vol. } 8 \text {, exp. } 292\end{array}$ & 1866 \\
\hline \multirow[t]{2}{*}{ AGEH } & Tula, Gobierno, Hacienda, exp. 12, caja 108 & 1871 \\
\hline & $\begin{array}{l}\text { Beneficencia Pública, Establecimientos Asistenciales, Hospicio } \\
\text { de Pobres 5, exp. } 7\end{array}$ & 1877 \\
\hline AHSS & $\begin{array}{l}\text { Beneficencia Pública, Establecimientos Asistenciales, Casa de } \\
\text { Niños Expósitos, leg. 1, exp. } 7\end{array}$ & 1889 \\
\hline \multicolumn{3}{|c|}{ Café } \\
\hline- & Estadística Mercantil, 25 de marzo c & 1858 \\
\hline \multirow[t]{3}{*}{-} & El Regenerador, 14 de junio de 1859 & 1859 \\
\hline & $\begin{array}{l}\text { Establecimientos Hospitalarios, Hospitales y Hospicios. Hospi- } \\
\text { tal de San Hipólito, leg. 1, exp. } 20\end{array}$ & 1866 \\
\hline & $\begin{array}{l}\text { Beneficencia Pública, Establecimientos Hospitalarios, Hospital } \\
\text { del Divino Salvador, leg. 10, exp. } 27\end{array}$ & 1868 \\
\hline \multirow[t]{3}{*}{ AHSS } & $\begin{array}{l}\text { Establecimientos Asistenciales, Casa de Niños Expósitos, Admi- } \\
\text { nistración, libros } 43,53\end{array}$ & $1880,1882,1883$ \\
\hline & $\begin{array}{l}\text { Beneficencia Pública, Establecimientos Hospitalarios, Hospital } \\
\text { de San Andrés, leg. } 5 \text {, exp. } 35\end{array}$ & 1884 \\
\hline & $\begin{array}{l}\text { Establecimientos Asistenciales, Casa de Niños Expósitos, leg. 3, } \\
\text { exp. } 10\end{array}$ & 1893 \\
\hline \multirow[t]{2}{*}{ AGEH } & Tula, Gobierno, Hacienda, caja 204, exp. 26 & 1900 \\
\hline & Jabón & \\
\hline- & $\begin{array}{l}\text { Mexico 1701-1813 [Main Database, Latin America], en } \\
\text { http://gpih.ucdavis.edu/index.html [Consultado: } 6 \text { de junio de } \\
\text { 2015]. }\end{array}$ & $\begin{array}{l}1756-1759,1784- \\
1785,1791,1794- \\
1795,1798-1803\end{array}$ \\
\hline
\end{tabular}


Fondos de Establecimientos Hospitalarios y Asistenciales, Hos-

ASS pitales y Hospicios, Hospicio de Pobres, libro 4

Establecimientos Asistenciales, Casa de Niños Expósitos, Administración, libros 8 y 14

AHCSIL Estante 17, tabla 1, vol. 3

Beneficencia Pública, Establecimientos Hospitalarios, Hospital

AHss de San Hipólito, leg. 1, exp. 4

Beneficencia Pública, Establecimientos Hospitalarios, Hospital

del Divino Salvador, leg. 11, exp. 25 y leg. 17, exp. 37

AGEH Tula, Gobierno, Hacienda, exp. 3 caja n. 147

\section{Velas}

Fondos de Establecimientos Hospitalarios y Asistenciales, Hospitales y Hospicios Hospicio de Pobres, libro 5

Beneficencia Pública, Establecimientos Hospitalarios, Hospital

AHss de San Hipólito, leg. 1, exp. 4

Beneficencia Pública, Establecimientos Hospitalarios, Hospital del Divino, leg. 11, exp. 25

Casa de Niños Expósitos, Administración, libro 63

- $\quad$ Gaceta de México, 14 de enero de 1784

AGEH Tula, Gobierno, Tesorería, exp. 10, caja 155

AHSS

Beneficencia Pública, Establecimientos Hospitalarios, Hospital de San Andrés, leg. 6, exp. 34
$1775-1778,1788-$

1825

1831-1836; $1845-$

$1846,1852,1854$

1857

$1860-1861$

1877,1889

1885

$1776-1778$

1861

1877

1886

1784

1887

$1889-1900$

\section{Carbón}

Fondos de Establecimientos Hospitalarios y Asistenciales, Hos- $\quad$ 1775, 1841

pitales y Hospicios, Hospicio de Pobres, libros 4 y 10

Establecimientos Hospitalarios y Asistenciales, Casa de Niños 1788-1813

Expósitos, Administración, libro 7

AHss Beneficencia Pública, Establecimientos Hospitalario, Hospital 1846, 1874

del Divino Salvador, leg. 1, exp. 4 y leg. 10, exp. 27

Fondos de Establecimientos Hospitalarios y Asistenciales, Casa 1847, 1850-1854;

de Niños Expósitos, Administración, libros 14, 53

Hospitales y Hospicios, Hospicio Terceros, leg. 1, exp. $12 \quad 1860,1861$

AHCMX Ayuntamiento y Gobierno del Distrito Federal, Abasto de carne, 1866

vol. 8, exp. 292

- $\quad$ Morales (2015, pp. 204-205)

$1872,1874,1876-$

$1879,1881,1889-$

1890

AHss Establecimientos Hospitalarios y Asistenciales, Hospitales y 1874

Hospicios, Hospital del Divino Salvador, libro 3

AHss Beneficencia Pública, Abastecimiento, Proveeduría, leg. 1, exp. 1887 26 
Archivos

AGEH Archivo General del Estado de Hidalgo, Pachuca, Hidalgo. AGn Archivo General de la Nación, Ciudad de México, México. AHH Archivo Histórico de Hacienda. AHCmx Archivo Histórico de la Ciudad de México, México. AHCsil Archivo Histórico del Colegio de San Ignacio de Loyola, Ciudad de México, México. AHMm-AC Archivo Histórico y Museo de Minería, Asociación Civil, Hidalgo, México. AHмm Archivo Histórico de Mineral del Monte, Hidalgo, México. AHPM Acervo Histórico y Palacio de Minería, Ciudad de México, México. aHss Archivo Histórico de la Secretaría de Salud, Ciudad de México. AHV Archivo Histórico de Veracruz, Veracruz, México

LISTA DE REFERENCIAS

Allen, R. (2001). The great divergence in European wages and prices from the middle ages to the first world war. Explorations in Economic History, 38(4), 411-447. DoI: 10.1006/exeh.2001.0775

Allen, R. et al. (2011). Wages, prices, and living standards in China, 1738-1925: In comparison with Europe, Japan, and India. The Economic History Review, 64(s1), 8-38. Dor: 10.1111/j.14680289.2010.00515.x

Allen, R., Murphy, T. y Schneider, E. (2012). The colonial origins of the divergence in the Americas: A labor market approach. The Journal of Economic History, 72(4), 863-894. Dor: 10.1017/S 0022050712000629

Arellano, M. (1976). Primera huelga minera en Real del Monte. México: PRI Comisión Nacional Editorial.

Arroyo, L. (2013). Inestabilidad, costo de vida y salarios reales en Venezuela en el siglo xix. América Latina en la Historia Económica, 20(3), 114. Dor: 10.18232/alhe.v20i3.551

Arroyo, L., Davies, E. y Van Zanden, J. (2012). Between conquest and independence: Real wages and demographic change in Spanish America, 1530-1820. Explorations in Economic History, 49(2), 149-166. DoI: 10.1016/j.eeh.2011.12.001

Bernstein, M. (1964). The Mexican mining industry, 1890-1950: A study of the interaction of politics, economics, and technology. Nueva York: University of New York.

Brading, D. (2015). Mineros y comerciantes en el México borbónico (1763-1810). México: Fondo de Cultura Económica.

Calderón, A. et al. (2017). New research guidelines for living standards, consumer baskets, and prices in Madrid and Mexico. En Working Papers (núm. 097). Università Commerciale Luigi Bocconi. Recuperado de https://ideas.repec.org/p/don/donwpa/097.html

Canudas, E. (2005). Las venas de plata en la historia de México: Síntesis de historia económica, siglo XIX. Tabasco: Universidad Juárez Autónoma de Tabasco/Utopía.

Carbajal, Á. (2013). Manual de nutrición y dietética (libro o Monografía (Manual), núm. 22755; p. 367). Madrid: Universidad Complutense. Recuperado de https://eprints.ucm.es/id/eprint/ $22755 /$

Carbajal, D. (2002). La minería en Bolaños, 1748-1810: Ciclos productivos y actores económicos. Jalisco: Colegio de Michoacán/Universidad de Guadalajara. 
Challú, A. y Gómez-Galvarriato, A. (2015). Mexico's real wages in the age of the great divergence, 1730-1930. Revista de Historia Económica/Journal of Iberian and Latin American Economic History, 33(1), 83-122. DoI: 10.1017/S021261091500004X

Chávez, L. (ed.). (1987). La situación del minero asalariado en Nueva España a fines del siglo xVIII. México: Centro de Estudios Históricos del Movimiento Obrero Mexicano.

Cherem, E. (2012). Estudio de la Canaive: ¿Cuánto mide México? El tamaño sí importa. Recuperado de https://www.animalpolitico.com/2012/02/cuanto-pesamos-ls-mexicans/

Cruz, S. (2016). Organización socioeconómica en el distrito minero de Pachuca (siglos XVII- XVIII). México: Universidad Autónoma del Estado de México. Recuperado de http://ri.uaemex.mx/handle $/ 20.500 .11799 / 64336$

Dobado, R. y García, H. (2010). Neither so low nor so short!: Wages and heights in eighteenth and early nineteenth centuries colonial Hispanic America. $x t^{\text {th }}$ World Economic History Congress, 1 48. Madrid. Recuperado de http://eprints.ucm.es/9762

Gaona, E. (2019). Trabajo, salarios y nivel de vida de los mineros de real del monte (México) en los siglos XVII y XIx (Tesis de doctorado). Universidad Autónoma de Barcelona, España.

García, V. (1989). Las panaderías, sus dueños y sus trabajadores. Ciudad de México, siglo XVIII. México: Ediciones de la Casa Chata. ciesas.

Garner, R. (2003). Precios y salarios en México durante el siglo XVII. En E. Cárdenas, Historia Económica de México (pp. 683-721). México: Fondo de Cultura Económica.

Gibson, C. (2003). Los aztecas bajo el dominio español: 1519-1810. México: Siglo XXI Editores.

Humboldt, A. (2011 [1822]). Ensayo político sobre el reino de la Nueva España. México: Porrúa.

Humphries, J. (2013). The lure of aggregates and the pitfalls of the patriarchal perspective: A critique of the high wage economy interpretation of the British industrial revolution: Critique of the high wage economy interpretation. The Economic History Review, 66(3), 693-714. DoI: 10.1111/j.1468-0289.2012.00663.x

Instituto Nacional de Estadística, Geografía e Informática [INEGI] (2000), Estadísticas Históricas de México [CD]

Khaustova, E. (2013). Prerevolution living standards: Russia 1888-1917. Moscow. En E. Khaustova (ed.), Prerevolution living standards: Russia 1888-1917. Moscú: Russian State Social University.

Langue, F. (1991). Trabajadores y formas de trabajo en las minas zacatecanas del siglo xviII. Historia Mexicana, 40(3), 463-506.

Levin, R., y Rubín, D. (2004). Estadística para administración y economía. México: Pearson Prentice Hall.

Llorca-Jaña, M. y Navarrete-Montalvo, J. (2015). The real wages and living conditions of construction workers in Santiago de Chile during the later colonial period, 1788-1808. Investigaciones de Historia Económica-Economic History Research, 11(2), 80-90. DoI: 10.1016/j.ihe.2014. 04.003

Martínez-Galarraga, J. y Prat, M. (2014). Wages and prices in early Catalan industrialization. UB Economics Working Papers (2014/305), 1-32.

Morales, H. y Reyes M. (2015). Indice de precios y salarios en la Puebla porfirista: 1876-1910. Terceras Jornadas de Historia Económica, Memorias (pp. 188-215). México: Asociación Mexicana de Historia Económica.

Moreno, R. (1976). Salario, tequio y partido en las ordenanzas para la minería mexicana del siglo xviII. Revista de la Facultad de Derecho de México, 101-102, 465-483. 
Panza, L. y Williamson, J. (2017). Australian exceptionalism? Inequality and living standards 18211871. Borrador: The University of Melbourne.

Quiroz, E. (2005). Entre el lujo y la subsistencia: Mercado, abastecimiento y precios de la carne en la ciudad de México. México: Colegio de México/Instituto de Investigaciones Dr. José María Luis Mora.

Saloma, A. (2000). Forjando la vida: Dichas y desdichas de las obreras de las fábricas cigarreras del porfiriato. Dimensión Antropológica, 7(18), 29-52.

Santilli, D. (ed.). (2020). Niveles de vida en un país en ciernes: Dimensiones de la desigualdad en la Argentina en el largo plazo, 1700-1900. Buenos Aires, Argentina: Prometeo libros.

Von Mentz, B. (2001). Trabajo minero y control social durante el porfiriato. Los operarios de dos poblaciones contrastantes. Historia Mexicana, 50(3), 555-607. 